\title{
Research on Mechanical Properties and Parameter Identification of Beam-Column Joint with Gusset Plate Angle Using Experiment and Stochastic Sensitivity Analysis
}

\author{
Xian Dong (iD) and Yadi Wang \\ School of Civil Engineering, Shijiazhuang Tiedao University, Shijiazhuang, Hebei 050043, China \\ Correspondence should be addressed to Xian Dong; wendongxian@163.com
}

Received 4 July 2021; Revised 6 October 2021; Accepted 15 October 2021; Published 11 November 2021

Academic Editor: Satheeskumar Navaratnam

Copyright ( 2021 Xian Dong and Yadi Wang. This is an open access article distributed under the Creative Commons Attribution License, which permits unrestricted use, distribution, and reproduction in any medium, provided the original work is properly cited.

\begin{abstract}
Based on stochastic sensitivity analysis, a new style of joint structure with greater ductility and higher strength-the beamcolumn joint with gusset plate angle (JGA) steel-was proposed. Research on the static and hysteretic behavior of the JGA was performed using finite element analysis and experimental methods. The research results indicated that adding a seat angle could increase the positive and negative initial rotational stiffness and strength and provide a better energy consumption performance of the joint. An improved chaotic particle swarm optimization (ICPSO) neural network algorithm was used to study the stochastic sensitivity. Seven important parameters that influence the bending stiffness and strength of the JGA, namely, the beam height, beam flange width, beam web thickness, gusset plate thickness, connection angle steel thickness, connection angle steel width, and seat angle steel thickness, were investigated by stochastic sensitivity analysis. Moreover, the beam height, connection angle steel, and seat angle steel thickness, which had significant influences on the mechanical properties of the joints, were studied in depth by finite element analysis. Within the range of the parameters of the joint, the higher the beam height was, the larger the connection angle thickness was; the smaller the connection angle width was, the better the joint performance was. A reasonable design of the JGA is proposed: a beam with the SH2 section $(250 \times 125 \times 6 \times 9 \mathrm{~mm})$ and a $10 \mathrm{~mm}$ thick and $75 \mathrm{~mm}$ long angle steel connection.
\end{abstract}

\section{Introduction}

A joint with gusset plate angle (JGA) connection is a new type of joint used to connect the brace and the beam or column of a frame. This plate connection joint has less rigidity but greater ductility while maintaining a higher strength. It can be used in a greater number of applications, avoiding brittle failure of the structure at the joints. This kind of joint is composed of a high-strength bolt, angle steel, and a gusset plate welded on the flange of the beam.

In the 1990s, a considerable amount of research on steel frame joints was carried out. Due to the complexity of the structure and boundary conditions of the angle beam-column joint with a gusset plate, gusset plates are designed based on design experience and elastic analysis. The design is then examined by effective width theory and Thornton theory [1-6]. This design method cannot fully account for this kind of joint's mechanical properties, the initial rotation stiffness, the rotation properties, and the ultimate bending capacity. Thus, the seismic behavior of the global structure cannot be estimated correctly. Considerable research on steel frame joints has been carried out in recent years. The notion that the influence of the gusset plate on the performance of the joint could not be neglected was raised by experiments [7-10]. After bearing a lateral force, considering the composite effect of the upper floor, the joint's strength could achieve $30 \%-40 \%$ of the plastic bending moment of the beam, and the articulated composite joint had good ductility and a strong semirigid performance [11]. These researchers used finite element analysis software to analyze the influences of the gusset plate on the rotational stiffnesses of articulated beam-column joints and on articulated 
concentrically braced frames. The results of their study showed that a hinge joint would become a semirigid joint when the influence of the gusset plate was taken into consideration, which would have a significant influence on the distribution of the internal forces of connecting members. Fahnestock et al. analyzed the flexural steel frame of full-scale beam-column double web angle-steel connection joints, explored the performances of nonductile braced frames, carried out dynamic analysis of multistory nonductile steel frames, and investigated the seismic capacities of frame structures [12]. Fang et al. carried out three fullscale tests where single-sided plate-type (unstiffened) splice members were adopted for two specimens and stiffened splice members were employed for the remaining specimen. Furthermore, design models were proposed to predict their ultimate strengths and governing failure modes accordingly $[13,14]$. Zhang et al. studied 12 specimens to examine the low-cycle fatigue behaviors of I-shaped steel bracing members with gusset plate connections, and a probabilistic model was proposed to predict the fatigue life by Bayesian updating [15].

In the study of joint structures, experimental and theoretical research has been based on the assumption that the structural design variables were completely determined, and the degree of influence of the design variable changes on the overall response of the structure was considered separately; that is, definite sensitivity analysis was performed. The purpose of stochastic sensitivity analysis is to analyze the influence degrees of different parameters on the overall effect of the model based on the combined changes of different parameters. This can be regarded as a comprehensive evaluation of the uncertainty analysis of random parameters by comprehensively analyzing the influence mode and degree of the design parameters on the structure model, determining which design parameters are more sensitive to changes in the structure, and judging the influence degree of different design parameters on the structure model [16-19].

Stochastic sensitivity analysis is more in line with the actual response of a structure. The finite element software ANSYS can carry out random sensitivity analysis, and the sampling process is based on the Monte Carlo method. Thus, the number of finite element simulations increases with the number of samples. As a result, due to the complexity of the joint model and the correlation of component parameters, the sensitivity coefficient can only be calculated for a small range of parameters. Due to the limitations on the number of tests that can be conducted and the finite element software capabilities, for complex structures, the finite element method and experimental methods can only be used to qualitatively analyze the influence of each component of the joint on the mechanical properties of the structure, and they cannot give the values of the influence factors.

An intelligent optimization algorithm-the improved chaotic particle swarm optimization algorithm [20-23]was used to analyze the stochastic sensitivity of the angle beam-column joint with a gusset plate. This method can establish an intelligent model with high precision, and it can also be used to analyze the stochastic sensitivity of a structure in the case of a large parameter variation range. Thus, the analysis results can be extended to the same type of joints. Therefore, in this study, first, both static testing and hysteretic testing were used to study the initial rotational stiffness, failure mode, and hysteretic behavior of the JGA. Second, multivariate analysis of several key parameters was performed to study the influence on the JGA's static properties with the finite element method (FEM) model and stochastic sensitivity analysis. Through the intelligent calculation method of a chaotic particle swarm optimization neural network, the components and sensitivity values that had a significant influence on the mechanical properties of the joint were analyzed. Finally, finite element modeling and analysis were performed for the parameters that had the greatest impact on the mechanical properties of the JGA to provide a reliable reference for engineering design.

\section{Experimental Analysis of the Joint}

In this section, the JGA experiments are discussed. Under a horizontal earthquake, after the brace failed, the axial force of the column mainly remained unchanged, while the joint moment changed alternately, and the inflection points of the beam and column were close to the midspan. Thus, the system can be simplified as a column under a static axial load and a joint under a static load. A typical element whose beam and column inflection points were both in the midspan was chosen for a common multiple-story centre-braced steel frame structure under a lateral load. Considering that the span of the beam is often 10-20 times the depth of the beam, the length of the cantilever section was $1 \mathrm{~m}$ and the height of the column was $2 \mathrm{~m}$. The specimen model is shown in Figure 1.

A test was divided into two groups: SJA and SJB. SJA was a static load test, and SJB was a hysteresis load test. Specimens of each group were divided into three types: a basic specimen, a specimen with added stiffeners to both sides of the column web in the location corresponding to the tops of the bolts, and a specimen with an added seat angle. Specimen information is shown in Table 1, and the details of the joints are shown in Figure 2. Hot-rolled H-shaped steel was used for the beam and column specimens, and their cross-sectional areas were the same. The cross-sectional area of the column was HM $244 \times 175 \times 7 \times 11 \mathrm{~mm}$, and the cross-sectional area of the beam was HM194 $\times 150 \times 6 \times 9 \mathrm{~mm}$. The steel of the beam, column, angle, and gusset plate was Q235. The bolts were 10.9-stage M16 friction-type high-strength bolts, and the torque method was used to fasten them. All of the butt welds were first-grade welds, and the welding rods were E43. All of the welding work was finished in a factory. Components were blasted before assembly, and the slip coefficient of the friction surface was 0.45 . Steel from the beam web, beam flange, column web, and column flange was chosen as the material for tension tests, and the average performance of the material is shown in Table 2. The static test results are shown in Figure 3, and the specific information can be found elsewhere [24]. 


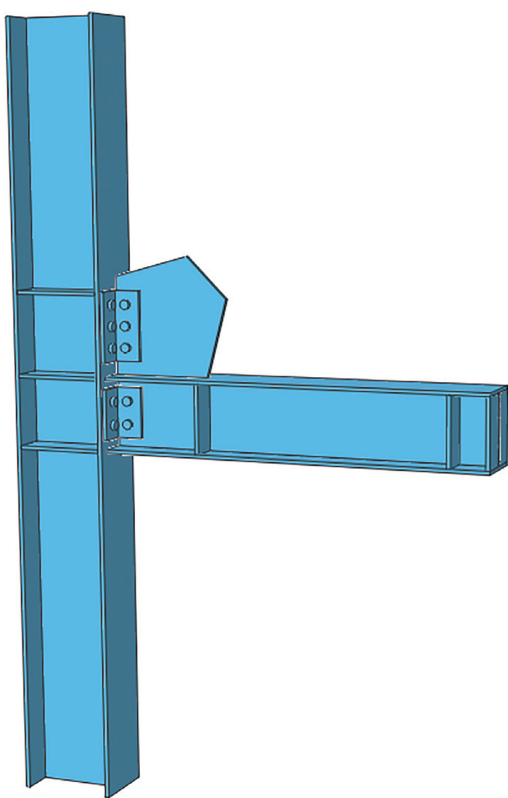

(a)

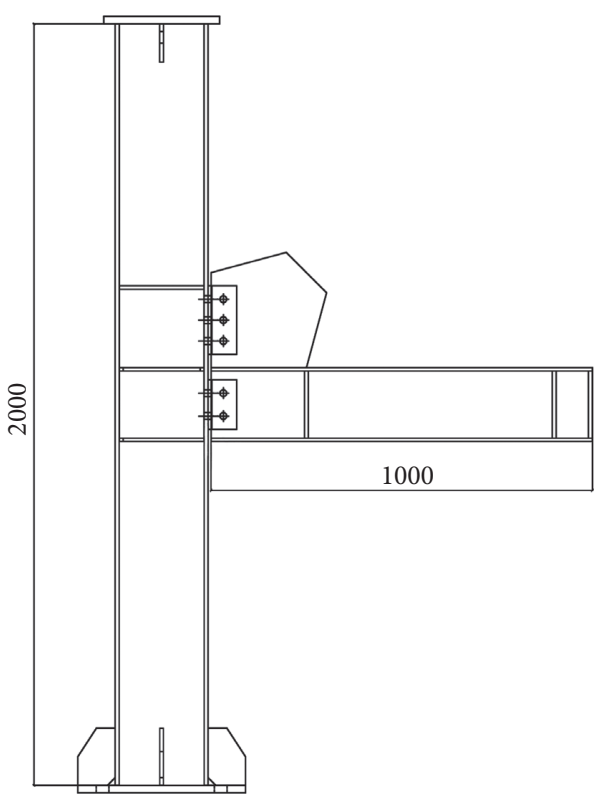

(b)

FIgURe 1: Specimen model (mm).

TABLE 1: Specimen information (mm).

\begin{tabular}{|c|c|c|c|c|c|}
\hline Number & Seat angle & $m$ & Vertical stiffener of the column & $D$ & Test type \\
\hline SJA-1 & None & 2 & None & 16 & Static monotonic \\
\hline SJA-2 & None & 3 & $176 \times 72 \times 10$ & 16 & Static monotonic \\
\hline SJA-3 & $\mathrm{L} 75 \times 75 \times 10 \times 150$ & 3 & $176 \times 72 \times 10$ & 16 & Static monotonic \\
\hline SJB-1 & None & 2 & None & 16 & Low-cycle repeated \\
\hline SJB-2 & None & 3 & $176 \times 72 \times 10$ & 16 & Low-cycle repeated \\
\hline SJB-3 & $\mathrm{L} 75 \times 75 \times 10 \times 150$ & 3 & $176 \times 72 \times 10$ & 16 & Low-cycle repeated \\
\hline
\end{tabular}

Note. $m$ is the number of column horizontal stiffeners; $D$ is the diameter of the bolts; $L$ is the steel shape.

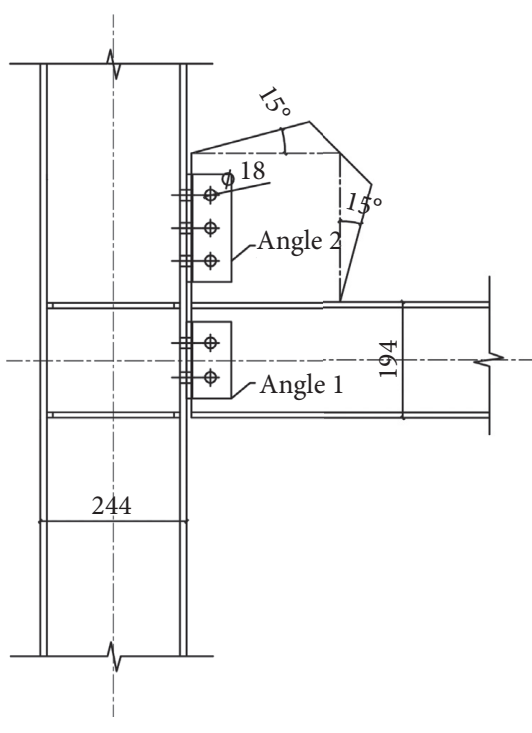

(a)

Figure 2: Continued. 

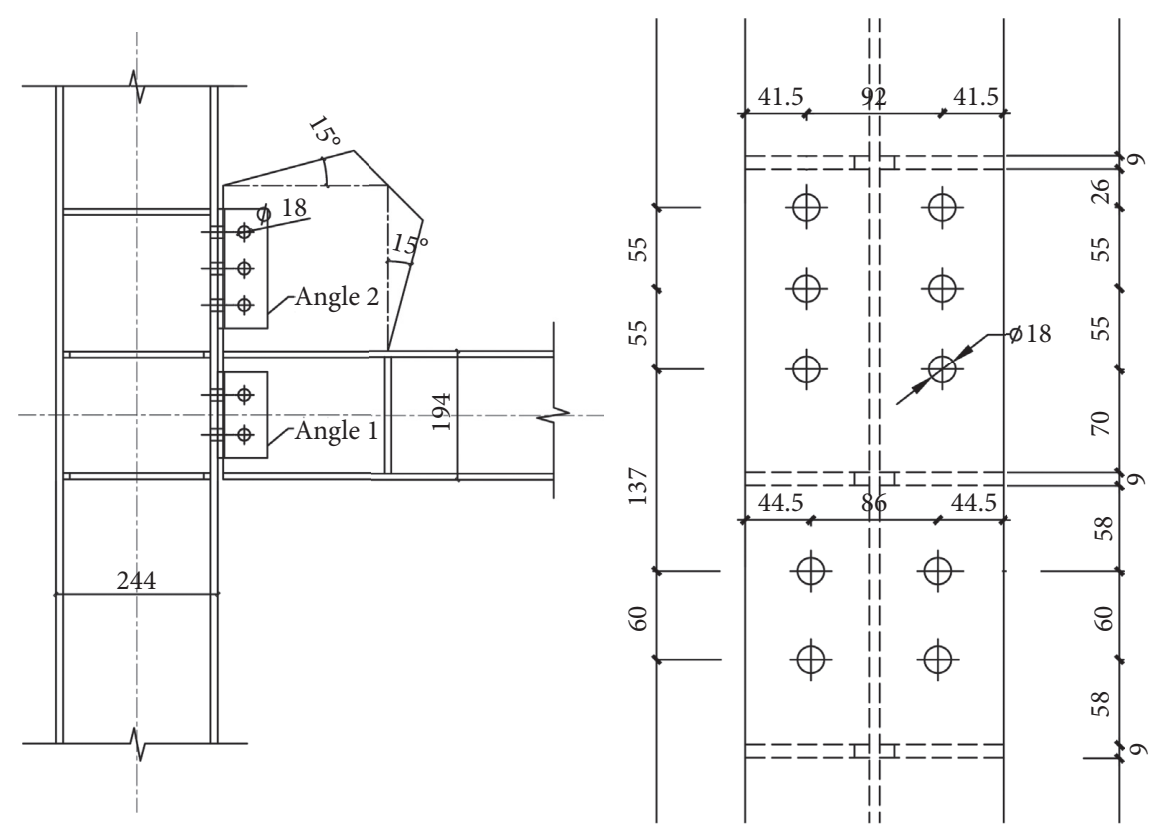

(b)
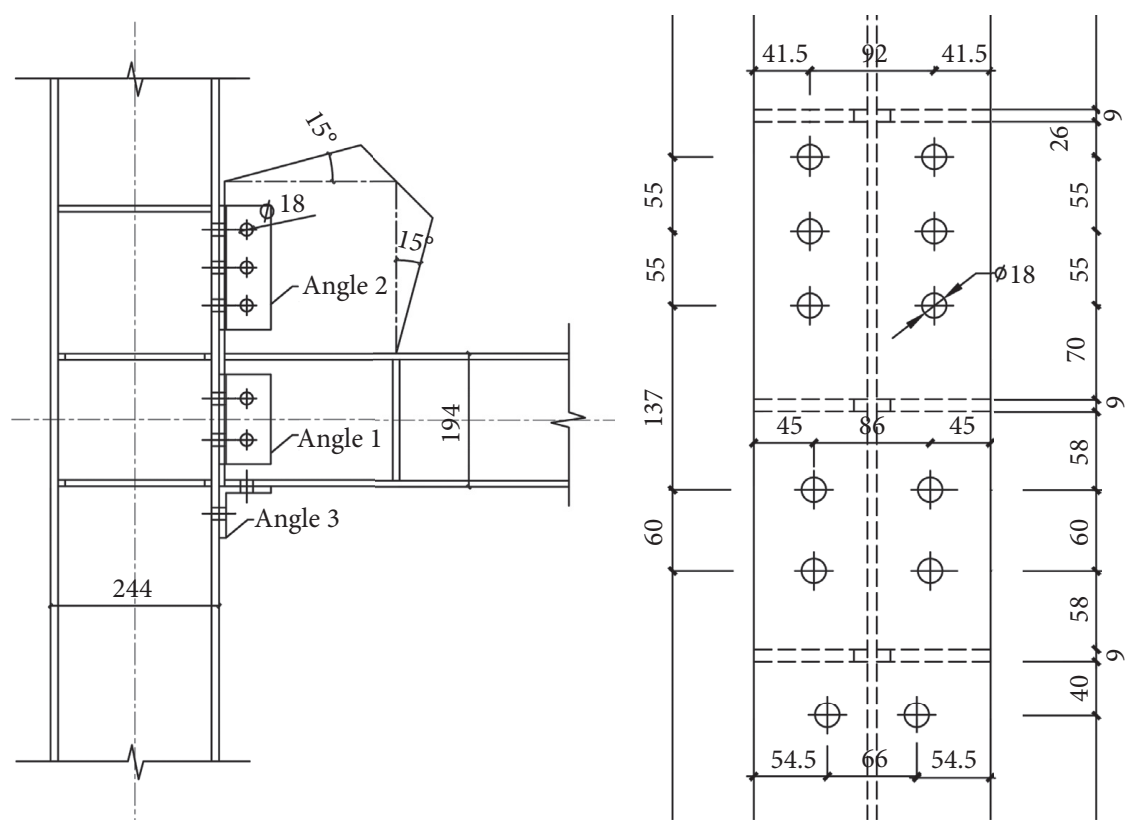

(c)

Figure 2: Details of the joints (mm). (a) SJA/B-1. (b) SJA/B-2. (c) SJA/B-3. Note. Angle 1 is the connection/web angle steel; angle 2 is the gusset angle steel; angle 3 is the seat angle steel.

TABle 2: Properties of steel material.

\begin{tabular}{ccccc}
\hline & $f_{y}$ & $f_{u}$ & $E\left(10^{5} \mathrm{~N} / \mathrm{mm}^{2}\right)$ & Elongation ratio (\%) \\
\hline Average of steel & 278 & 448 & 1.97 & 23.60 \\
\hline
\end{tabular}

Note. $f_{y}$ is the yield strength $\left(\mathrm{N} / \mathrm{mm}^{2}\right) ; f_{u}$ is the ultimate strength $\left(\mathrm{N} / \mathrm{mm}^{2}\right)$.

2.1. Quasi-Static Test of SJB. The whole specimen was installed on the loading frame. First, a $320 \mathrm{kN}$ axial load was applied to the end of the column by a hydraulic jack to create an axial compression ratio of 0.3 . A low-cycle repeated load was then applied by the MTS until the specimen failed. The loading procedure was as follows: 


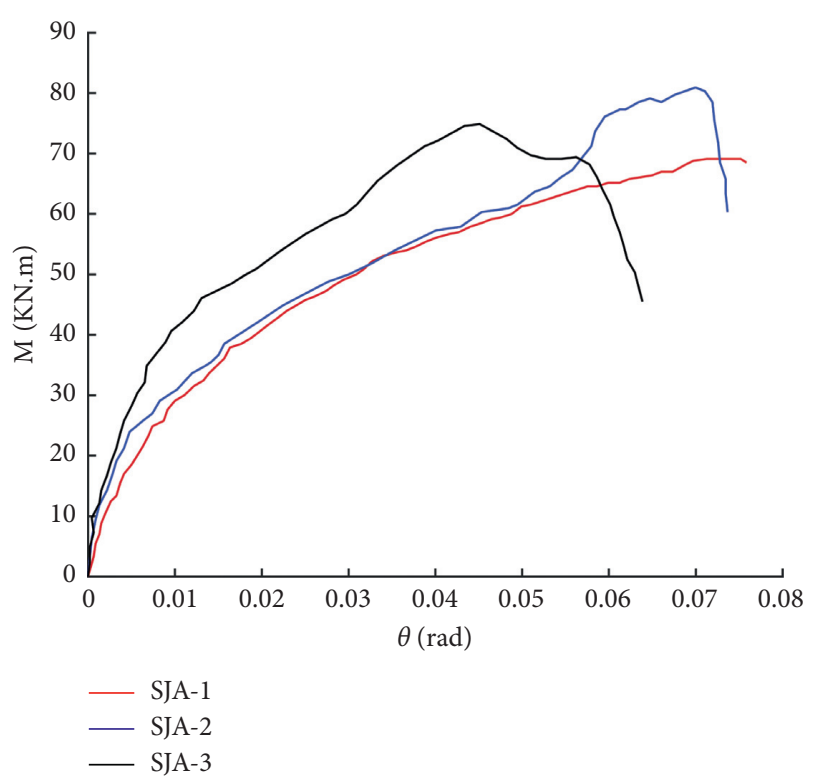

FIgURE 3: Moment-rotation curve of SJA.

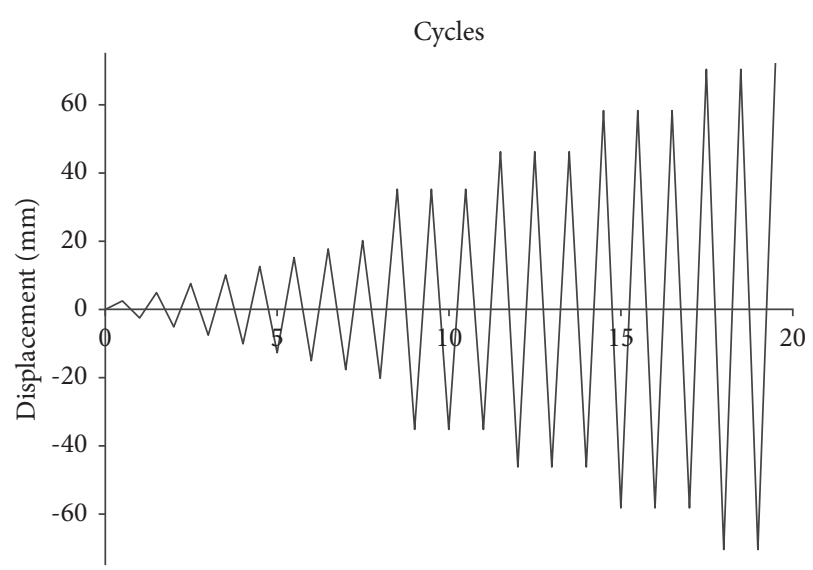

Figure 4: Loading system of the specimen.

(1) Before the test, a preload was applied. Vertical displacement was applied to the end of the beam as follows: apply load $+5 \mathrm{~mm}$ (compression) $\longrightarrow$ unload to $0 \longrightarrow$ apply opposite load $-5 \mathrm{~mm}$ (tension).

(2) In the formal loading stage, a low-cycle repeated load was applied by the MTS system (displacement). The loading system of the specimen is shown in Figure 4. Before the specimen yielded, the step difference was $2.5 \mathrm{~mm}$, and each step went through one cycle. After yielding, the step difference was increased by multiples of the yielding displacement until the specimen failed.

2.1.1. Experimental Results for SJB-1. When the positive load reached a displacement of $30 \mathrm{~mm}$, in addition to the largescale yield of the gusset angle steel, the column flange connected with the uppermost row of bolts began to show a yield point. When the negative load reached a displacement of $30 \mathrm{~mm}$, the negative peak load was $47 \mathrm{kN}$, while the distance between the lower flange of the beam and the column significantly increased. When the positive load reached a displacement of $45 \mathrm{~mm}$, frequent slip noise occurred, the gap between the top section of the gusset angle steel and the column flange increased, the top of the gusset angle steel underwent significant buckling deformation, showing warping deformation with the bolt as the fulcrum, and cracks appeared at the intersection of the two limbs. When the negative load reached a displacement of $45 \mathrm{~mm}$, the lower part of the beam web yielded under tension, and the panel zone yielded under compression. When the positive load reached a displacement of $60 \mathrm{~mm}$, the cracks of the gusset angle steel significantly expanded and had a tendency to become destroyed. With the distal end of the gusset plate as the demarcation point, the beam could be significantly deformed.

The final failure mode was as follows. When forward loading was continued to $87 \mathrm{~mm}$, the gusset angle steel fractured and failed (as shown in Figure 5). During the entire cyclic loading process, forward and reverse slippage basically occurred within the same corner range of the hysteresis curve. Shear deformation was evident in the joint area when it failed.

2.1.2. Experimental Results for SJB-2. When the positive load reached a displacement of $30 \mathrm{~mm}$, the gap at the top of the gusset angle steel was slightly enlarged, and small cracks appeared at the intersection of the two limbs, as shown in Figure 6(a). When the load was negatively applied to a displacement of $30 \mathrm{~mm}$, a small gap (1-2 mm) appeared between the bottom end of the web angle steel and the column flange, as shown in Figure 6(b), and the gap between the top of the gusset angle steel and the column flange closed. When the positive load reached a displacement of $45 \mathrm{~mm}$, the gusset angle steel underwent significant warpage (maximum distance of $2.5-3 \mathrm{~mm}$ from the column flange), the cracks on it began to develop rapidly, as shown in Figure 6(c), and the gap between the web angle steel and the column flange closed. The lower flange of the beam end and the lower flange of the column were completely tightened, and the bearing capacity was greatly improved. When the load was negatively applied to a displacement of $45 \mathrm{~mm}$, there was a gap of 3-4 mm between the bottom end of the web angle steel and the column flange, and a tiny gap $(<1 \mathrm{~mm})$ was also generated at the bottom of the gusset angle steel.

The final failure mode was as follows. When the positive load reached a displacement of $60 \mathrm{~mm}$, one side of the gusset angle steel fractured, generating a loud noise, and a deep crack appeared on the other side, which was about to fail, as shown in Figures 6(d) and 6(e). During the whole loading process, there was no visible deformation of the column web. A photograph of the damaged joint is shown in Figure 6(f).

2.1.3. Experimental Results for SJB-3. When the positive load reached a displacement of $30 \mathrm{~mm}$, small cracks and slight warping appeared in some parts of the gusset angle steel. 


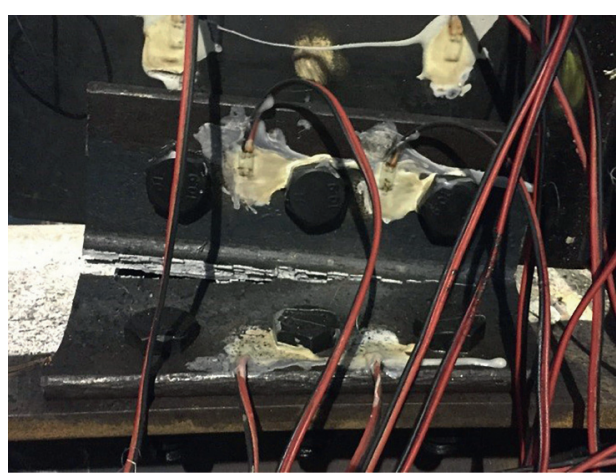

(a)

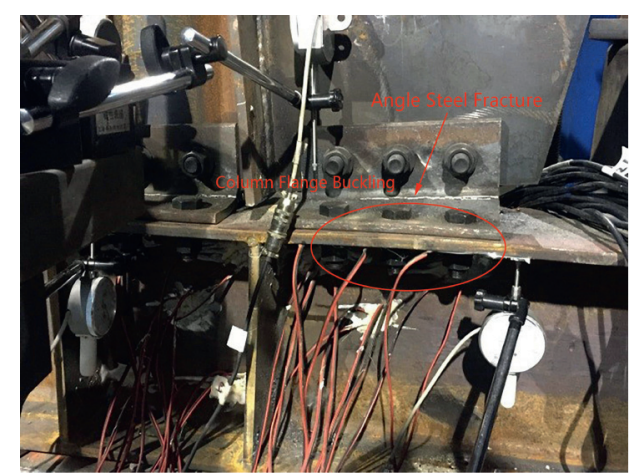

(b)

Figure 5: Fracture form of SJB-1. (a) Gusset angle steel fracture $(87 \mathrm{~mm})$. (b) Angle steel fracture + column flange buckling (87 mm).

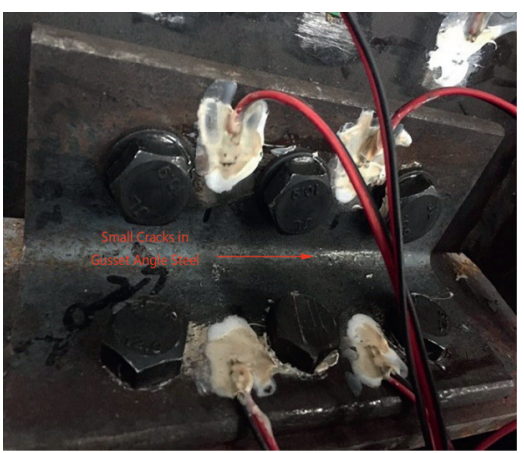

(a)

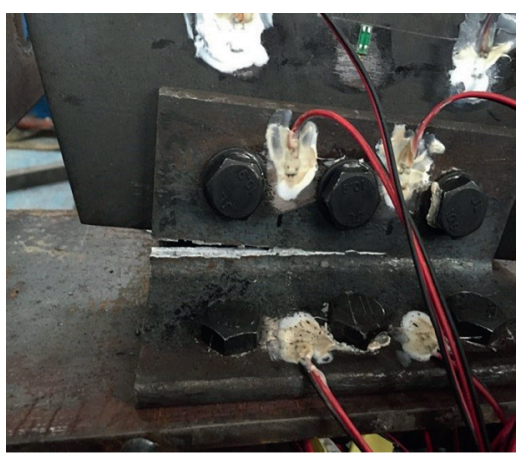

(d)

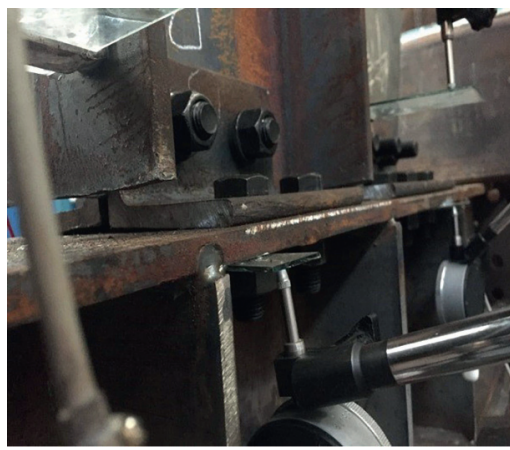

(b)

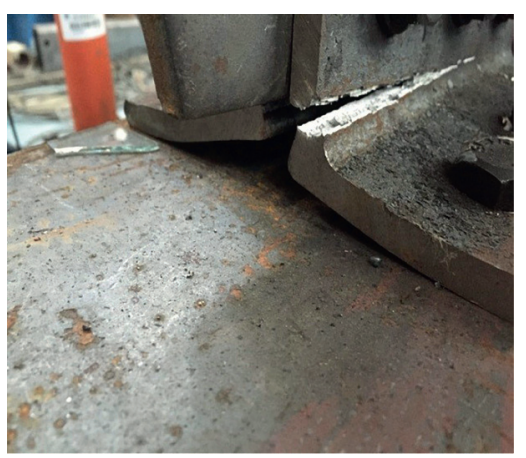

(e)

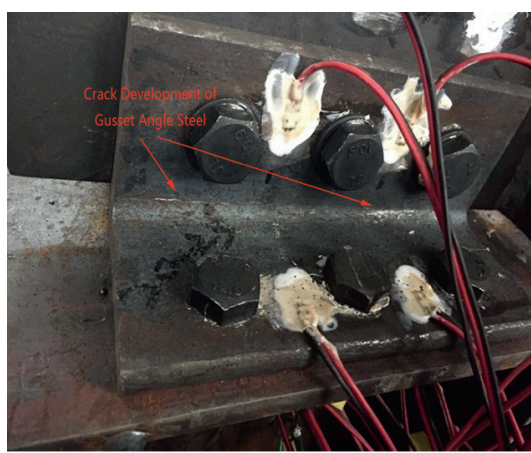

(c)

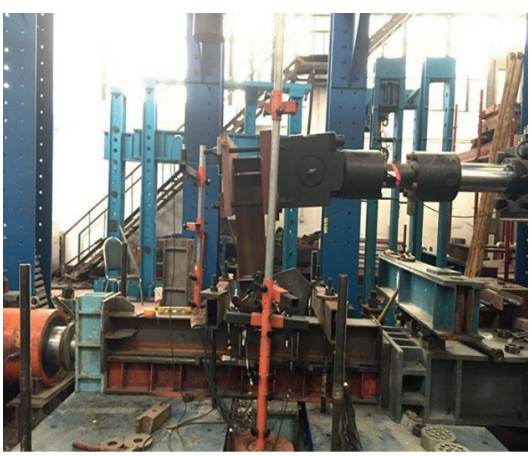

(f)

Figure 6: Failure mode of SJB-2. (a) Small cracks in gusset angle steel $(30 \mathrm{~mm})$. (b) Gap between web angle steel and column flange $(-30 \mathrm{~mm})$. (c) Crack development of gusset angle steel $(45 \mathrm{~mm})$. (d) Fracture failure of upper angle steel (60 mm). (e) Gusset angle steel warping on one side $(60 \mathrm{~mm})$. (f) Joint loading schematic.

When the negative load reached a displacement of $30 \mathrm{~mm}$, the seat angle steel warped and separated from the column flange, forming a gap $(3 \mathrm{~mm})$, and a small gap also appeared in the left web angle steel, as shown in Figure 7(a). After unloading, the gap between the seat angle steel and the column flange was not completely closed. When the positive load reached a displacement of $45 \mathrm{~mm}$, the gap between the top of the gusset angle steel and the flange of the column developed significantly, as shown in Figure 7(b). At the same time, there were significant gaps between the column flange and the angle steel, which included the left lower part of the gusset angle steel and the left lower part of the web angle steel, and the right gap between the seat angle steel and the column flange was still not completely closed, as shown in Figure $7(\mathrm{c})$. When the negative load reached a displacement of $45 \mathrm{~mm}$, the seat angle severely buckled and deformed, and deep cracks formed from the right side, as shown in Figure $7(d)$. 


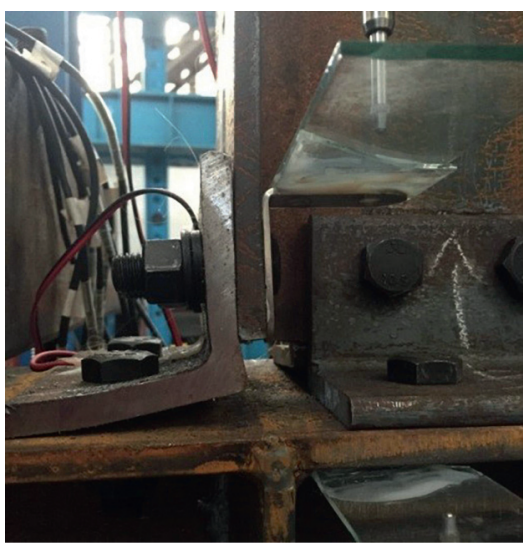

(a)

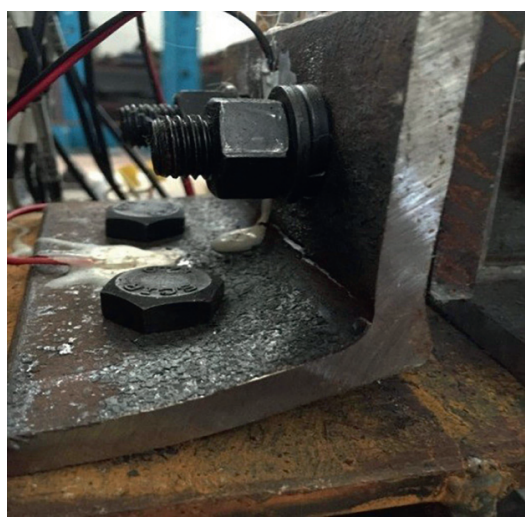

(d)

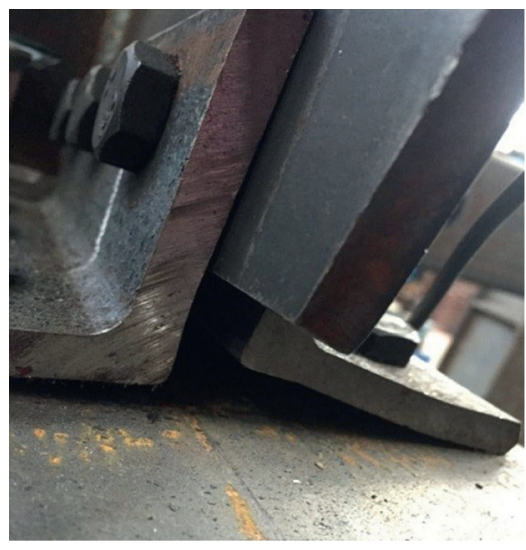

(b)

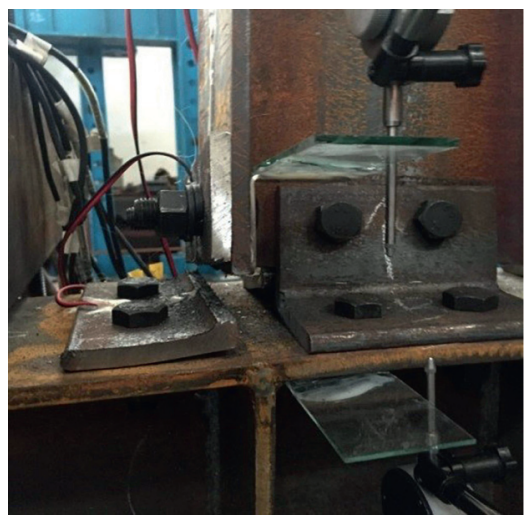

(e)

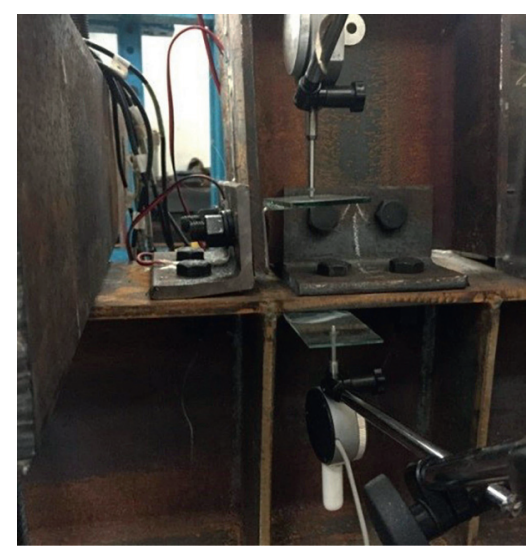

(c)

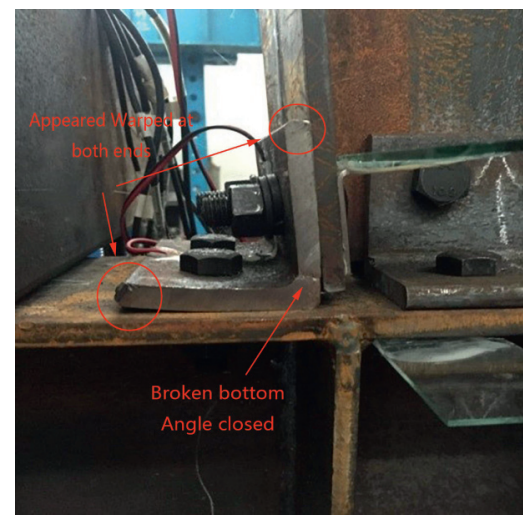

(f)

Figure 7: Deformation and failure form of SJB-3. (a) Seat angle warpage ( $-30 \mathrm{~mm})$. (b) Gap between upper angle steel and column flange $(45 \mathrm{~mm})$. (c) Right gap between seat angle steel and column flange $(45 \mathrm{~mm})$. (d) Seat angle steel deep crack $(-45 \mathrm{~mm})$. (e) Seat angle steel fracture $(-60 \mathrm{~mm})$. (f) Broken seat angle closed and appeared warped at both ends $(60 \mathrm{~mm})$.

The final failure mode was as follows. When the negative load reached a displacement of $60 \mathrm{~mm}$, the seat angle steel broke and separated, and soon cracks appeared on the web angle steel, as shown in Figure 7(e). The gap between the column flange and the web angle steel increased. Loading was continued to a positive displacement of $60 \mathrm{~mm}$, and the broken seat angle was closed. The bolt was used as a fulcrum, showing a state of warping at both ends, as shown in Figure 7(f), which retained a certain pressure bearing capacity in the compression area. The hysteresis test results are shown in Table 3, and moment-rotation curves of SJB are shown in Figure 8.

2.2. Test Analysis. The hysteresis test results are shown in Table 3. The moment-rotation curves of SJB are shown in Figure 8. When the rotation angle of SJB- 1 was 0.003 , the joint began to yield, and the hysteresis curve was nonlinear. Due to the influence of bolt drift, a significant pinch phenomenon occurred. The hysteresis curve was not full and presented a $Z$ shape, indicating that the ductility of the specimen was relatively poor. After yielding, the peak load of the second circle was less than that of the first circle, but the decrease was within $7 \%$. Meanwhile, a pinch phenomenon was more evident than that in the first circle, which indicated that stiffness degradation occurred. Compared with the positive performances, the negative stiffness, ultimate moment, and ultimate rotational angle of the joint were all small; they were $87 \%, 63 \%$, and $83 \%$ of the corresponding positive performances, respectively. The negative peak load and stiffness of the joint were more significant than the positive peak load and stiffness, and the negative structure of the joint was weak.

The overall shape and trend of the hysteresis curve of SJB-2 were consistent with those of specimen SJB-1. Compared with SJB-1, a positive initial rotational stiffness and each step peak load of SJB-2 increased by $22 \%$ and $26 \%$, respectively, and the negative behaviors showed no significant changes. This indicated that setting the stiffener at the beam web and column web corresponding to the end of the gusset plate could avoid probable damage due to local buckling of the column and beam flanges caused by local stress in a way that increased the joint's positive stiffness and strength (the failure mode was tension in the upper part and compression in the lower part), while it had a small influence on the negative behavior of the joint. The stiffener had a small influence on the energy consumption performance of the joint, but it could influence the static performance of the joint, which could affect the hysteresis performance of the joint indirectly. 
TABLE 3: Hysteresis test results.

\begin{tabular}{|c|c|c|c|}
\hline $\begin{array}{l}\text { Mechanical } \\
\text { indices }\end{array}$ & SJB-1 & SJB-2 & SJB-3 \\
\hline$M_{p}$ & $46 /-44$ & $58 /-36$ & $69 /-68$ \\
\hline$\theta$ & $0.086 /-0.063$ & $0.062 /-0.055$ & $0.059 /-0.047$ \\
\hline K & $4867 /-4212$ & $5936 /-4565$ & $7687 /-7960$ \\
\hline Failure modes & $\begin{array}{c}\text { Top angle + web angle cracked + local buckling of } \\
\text { column flange }\end{array}$ & $\begin{array}{l}\text { Top angle fractured }+ \text { local buckling of } \\
\text { column flange }\end{array}$ & $\begin{array}{l}\text { Seat and top angle } \\
\text { fractured }\end{array}$ \\
\hline
\end{tabular}

Note. $M_{p}$ is the plastic moment when the rotation angle was $0.03 \mathrm{rad}(\mathrm{kN} \cdot \mathrm{m}) ; K$ is the initial rotational stiffness of the joint $\left(\mathrm{kN} \cdot \mathrm{m} \cdot \mathrm{rad}^{-1}\right) ; \theta$ is the maximum rotational angle of the joint (rad).

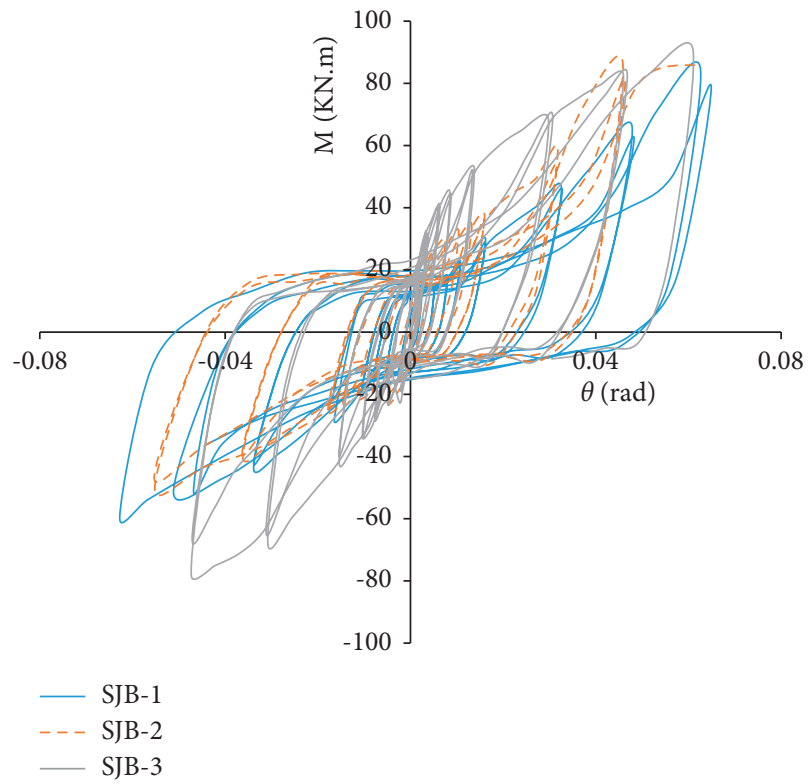

FIgURE 8: Moment-rotation curves of SJB.

A new component of the seat angle was added for SJB-3. Due to the drastic decrease in the drift, the hysteresis curve showed a spindle shape $(<0.011 \mathrm{~mm})$ in the early stage and an $S$ shape after the joint yielded. The curve was relatively full, and the energy consumption performance was significantly improved compared with SJB-1 and SJB-2. Each step of the peak load and the positive and negative initial rotational stiffness of the joint were greatly improved compared with those of SJB-2. The positive initial rotational stiffness and moment bearing capacity at $0.03 \mathrm{rad}$ increased by $30 \%$ and $19 \%$, respectively, compared with those of SJB-2. The corresponding negative performances increased $74 \%$ and $89 \%$, respectively. The ultimate rotational angle decreased slightly, with the positive and negative values decreasing by $4.8 \%$ and $14.5 \%$ compared with those of SJB-2, respectively. However, it was still larger than $0.03 \mathrm{rad}$ of the joint's maximum rotational angle [25], which indicated that setting the seat angle could increase the overall joint stiffness and strength significantly at the expense of losing a small amount of rotational performance. This could improve the energy consumption performance of the joint integrally.

A bolt drift phenomenon occurred during the whole loading process. The main reasons for this were the structural gap caused by machining error, the reserved hole of the high-strength bolt when installing, and the eccentricity of the high-strength bolt, which influenced the overall performance of the joint. SJB-1 was influenced most significantly, and SJB-3 was influenced less.

Based on the different structural forms of the specimens, the failure modes were mainly local buckling of the column flange, gusset angle fracture, local buckling of the beam web, local buckling of both flanges of the beam, buckling of the gusset plate zone, buckling of the column web in the panel zone of the joint, and seat angle fracture. Gusset angle cracking, local buckling of the top flange of the column, and seat angle cracking were the main failure modes. The failure mode of the angle beam-column joint with a gusset plate and seat angle was seat and gusset angle fracture. However, without the seat angle, the failure mode was local buckling of the column flange and gusset angle fracture.

According to the hysteresis tests, after the angle beamcolumn joint with a gusset plate buckled, degradation of the negative initial rotational stiffness and strength of the joint were more severe than those for positive values. Setting the stiffener could increase the positive initial rotational stiffness and strength of the joint. However, it had a small influence on the negative stiffness and strength, and it had a small influence on the energy consumption (or ductility) of the joint. Adding a seat angle could increase the positive and negative initial rotational stiffness and strength of the joint significantly at the expense of losing less rotational performance. It increased the negative initial rotational stiffness and strength of the joint more significantly, which provided a better energy consumption performance of the joint.

\section{Finite Element Analysis}

Finite element models were built for the test scale models in Section 2 to provide a basis for the parametric analysis. The boundary conditions and load application of the finite element models were consistent with those of the tests. The top and bottom of the column were fixed-end boundary conditions, and axial compression was applied to the top of the column. Constraints that restricted the beam to lateral displacement and torsion were applied on the lateral side of the beam. The loading sequence was the same as that in the experiments; that is, $110 \mathrm{kN}$ of bolt pretension and $320 \mathrm{kN}$ of axial compression on the column and load were applied on the end of the beam in turn. Displacement loading was used for the finite element models for loading convenience and to avoid premature convergence of the model. To consider the 
strengthening effect after the steel yielded, a three-brokenline constitutive model was used, as shown in Figure 9. The property test data in Section 2 were used for the constitutive model parameters of steel.

The comparisons of the ultimate failures of specimens SJA-1, SJA-2, and SJA-3 with the finite element model results are shown in Figures 10-12, respectively. The comparison of the moment-rotation curves between the static loading test and finite element analysis is shown in Figure 13. The comparison of the moment-rotation curves between the SJB test performance and the finite element analysis is shown in Figure 14, and it included a comparison of their backbone curves. A comparison of the moment bearing capacity under the same rotational angle between the SJA test performance and the finite element analysis is shown in Table 4. A comparison of the moment bearing capacity under the same rotational angle between the SJB test performance and the finite element analysis is shown in Table 5 .

As shown in Figures 10-12, the ultimate failure states obtained using the finite element method were similar to those in the experiments. As shown in Figure 13, the moment-rotation curve of the joint was linear initially, which indicated that the joint was in an elastic stage. The momentrotation curve of the FEM results agreed well with the experimental results in the elastic stage. In the stage after yielding, due to the simplification of the constitutive equation of the material and the experimental error, there were some inevitable errors, but the general trend was correct. When the rotation angle was less than $0.03 \mathrm{rad}$, the differences between the FEM results and test results were small and controlled to within $10 \%$.

Figure 14 shows that the simulated and experimental results agreed closely. When the load was on the first lap of each step, the hysteresis curve was relatively full. The curve generally pinched when the load was on the second lap. This was due to the slip and stiffness degradation of the specimen being reflected in the hysteresis curve, which was consistent with the experimental results. The peak values of the finite element model were always slightly larger than the experimental values because there were no defects in the machining assembly. The pinch phenomenon of the second hysteresis loop of the SJB-3 finite element model was not evident. As shown in Table 4, when the rotation angle was less than $0.03 \mathrm{rad}$, the differences between the FEM and experimental results were within $10 \%$.

As shown by the backbone curves, the finite element results fit well in the initial stage. The proportional ultimate load of the test specimen was slightly smaller than that of the finite element model, and the proportional limit angle of the specimen was less than that of the finite element model due to the reduction of the joint bearing and rotational capacities caused by the actual specimen error and the unnecessary gaps when installed. As the loading continued, the test and numerical analysis curves tended to be consistent, indicating that the overall choice of materials and the establishment of the model were accurate. Thus, the established model has reference value.

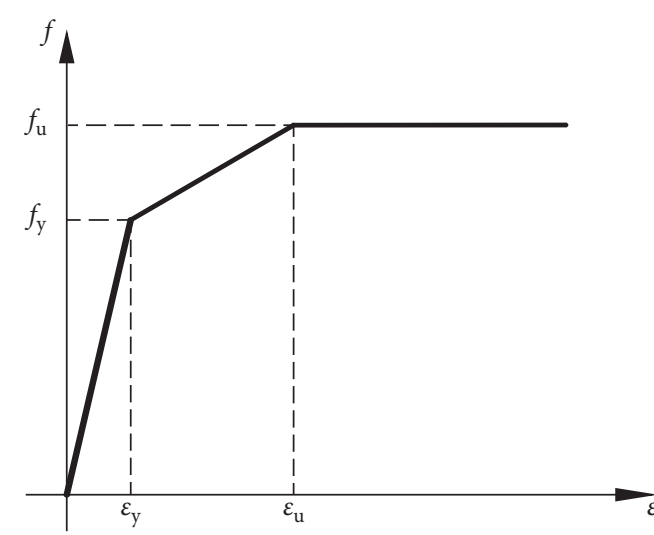

FIGURE 9: Constitutive curve of steel.

\section{Stochastic Sensitivity Analysis of Joint Parameters}

Sensitivity analysis of the structure can determine the degree of influence of each component on the structural performance. The improved chaotic particle swarm optimization (ICPSO) method was used to conduct stochastic sensitivity analysis on the static performance of the joint, and the sensitivity calculation results were compared with those of the ANSYS Probabilistic Design System (PDS). The parameters in the algorithm were set as follows: the population size of the particle swarm was 150 , the maximum number of iterations was 50 , and the number of iterations of the chaotic map was 30 . The steps of the chaotic processing for the particle swarm were as follows.

The variables become chaotic by chaotic searching. The logistic model is as follows:

$$
x_{n+1}=\mu-x_{n}^{2}, \quad n=1,2, \ldots,
$$

where $\mu$ is a control parameter that decides the state of the system. The system is totally in a chaotic state when $\mu=2$. The chaotification process is as follows:

(1) Map $x_{i, v}$ into the interval $[-2.0,2.0]$ using the equation

$$
h x_{i, v}=\frac{4 x_{i, v}-2\left(b_{v}+a_{v}\right)}{b_{v}-a_{v}}
$$

where $x_{i, v}$ is the location of particle $x_{i}$ in the $v$-th dimension and $\left[a_{v}, b_{v}\right]$ is the domain of $x_{i, v}$ in the $v$-th dimension.

(2) Generate a chaotic sequence $h x_{i, v}^{1}, h x_{i, v}^{2}, \ldots, h x_{i, v}^{J}$ by iterating the equation $h x_{i}^{j+1}=2-h x_{i}^{j} j$ times.

(3) Map particles of the chaotic sequence to the primary search space using the function $x_{i, v}^{j}=(1 / 4)\left\{2 b_{v}+2 a_{v}+h x_{i, v}^{j}(b v-a v)\right\}$. The chaos column points $x_{i}^{j}=\left(h x_{i, 1}^{j}, h x_{i, 2}^{j}, \ldots, h x_{i, n}^{j}\right)$ in each dimensional chaotic sequence can be derived from a Tent map [23].

The stochastic sensitivity is evaluated using the following indices: 

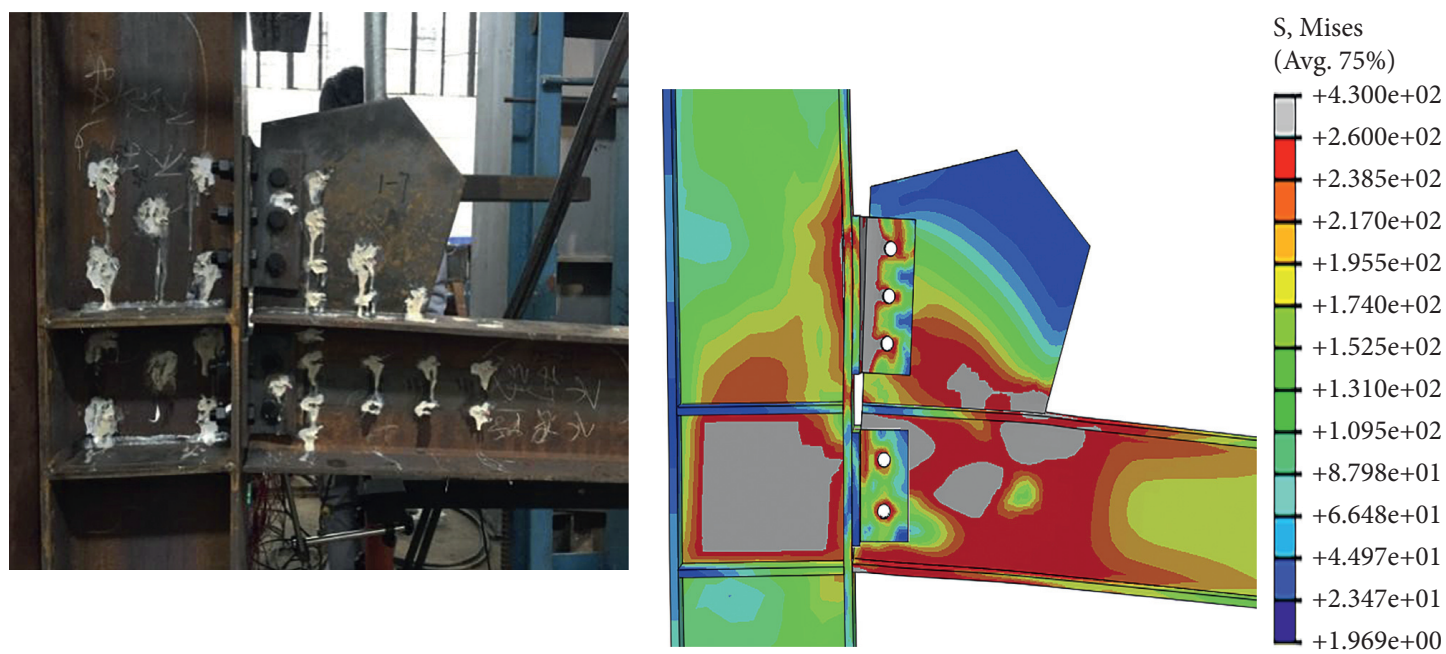

(a)

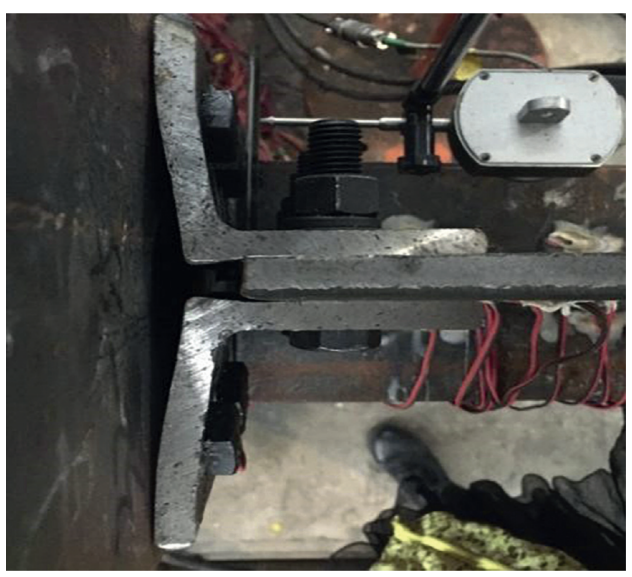

(c) (b)

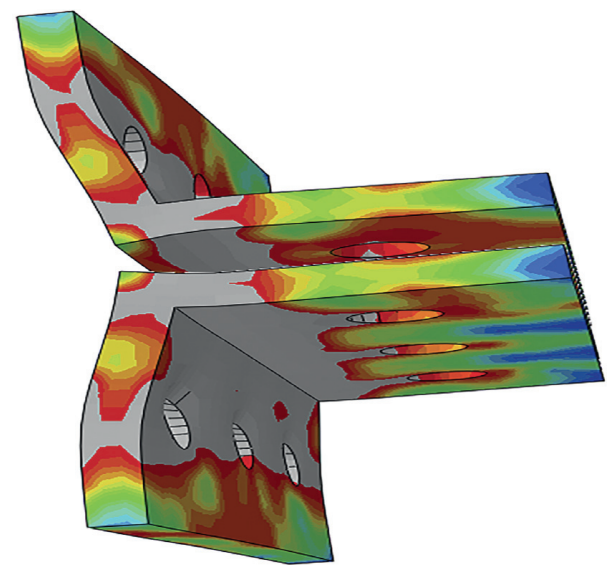

(d)

FIgURE 10: Comparison of ultimate failure states of SJA-1. (a) Overall test deformation. (b) Finite element deformation. (c) Gusset angle steel test deformation. (d) Gusset angle steel finite element deformation.

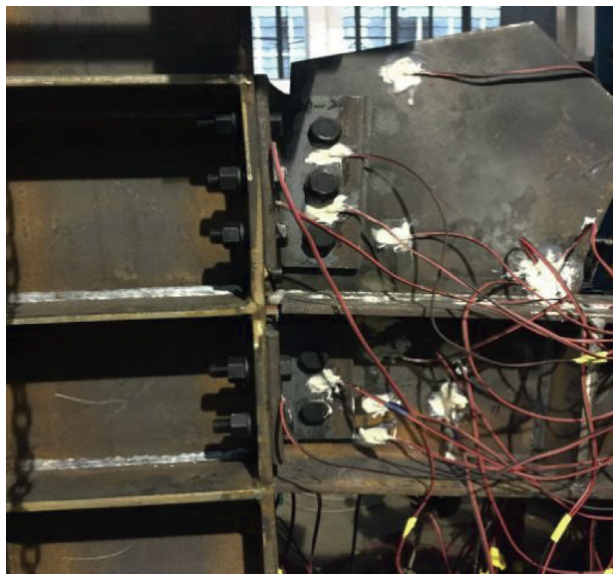

(a)

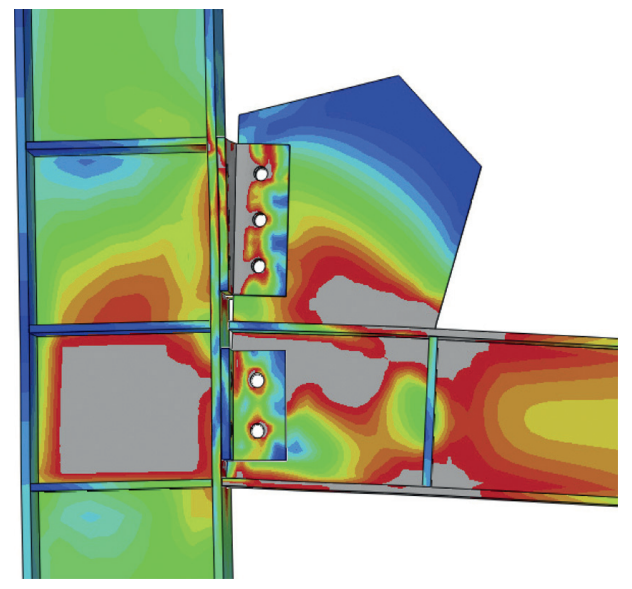

S, Mises (Avg. 75\%)

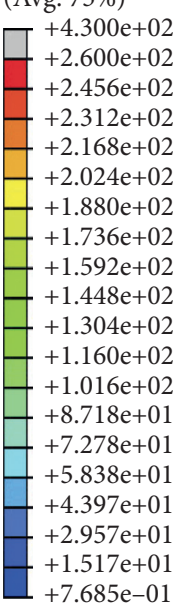

(b)

FIgURE 11: Continued. 


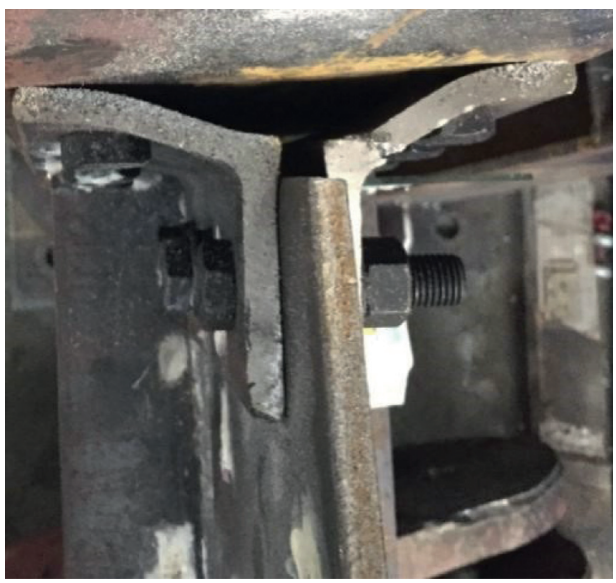

(c)

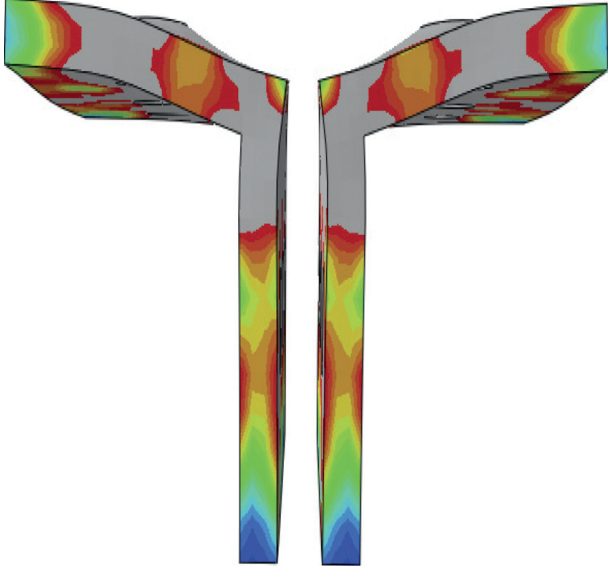

(d)

Figure 11: Comparison of ultimate failure states of SJA-2. (a) Overall test deformation. (b) Finite element deformation. (c) Gusset angle steel test deformation. (d) Gusset angle steel finite element deformation.

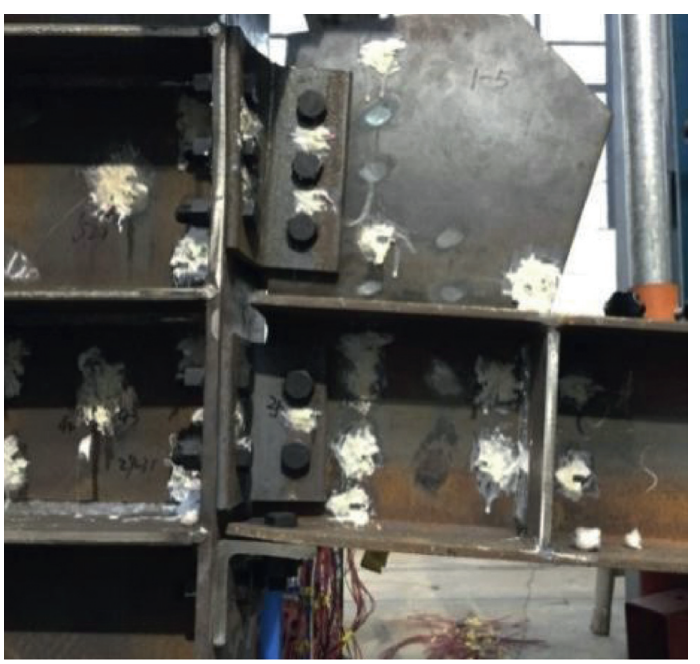

(a)

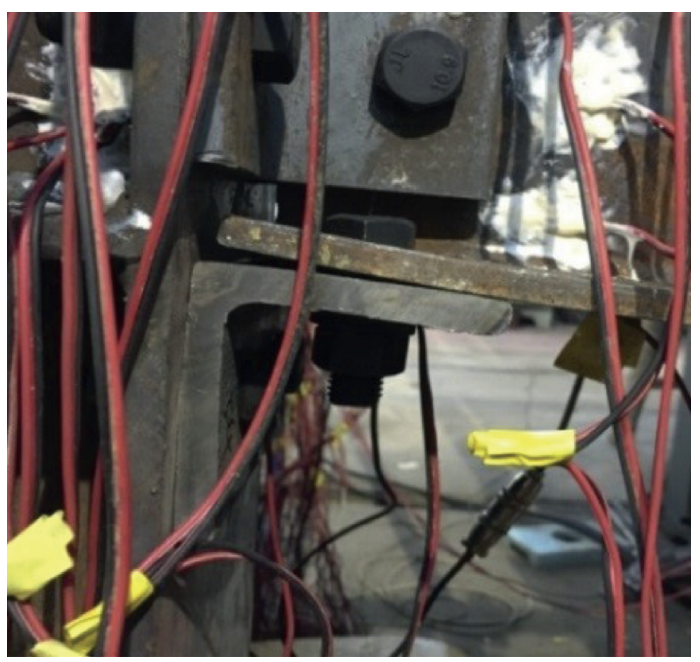

(c)

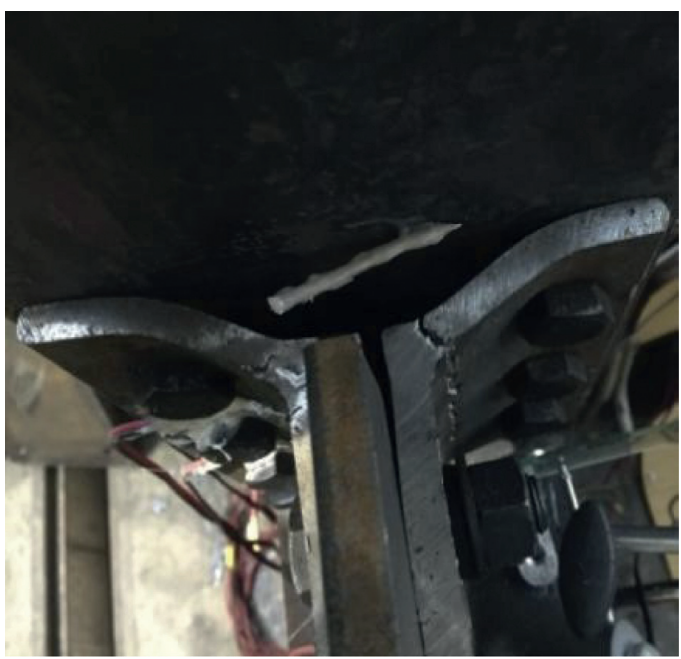

(b)

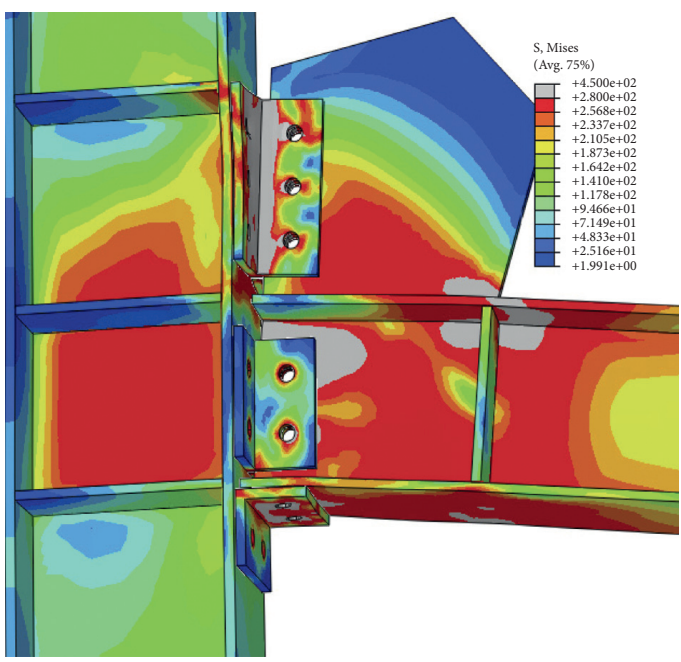

(d)

Figure 12: Continued. 


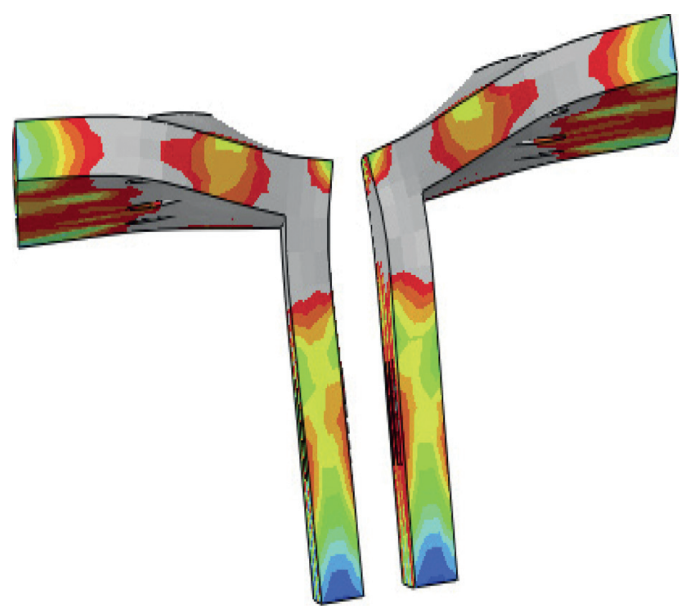

(e)

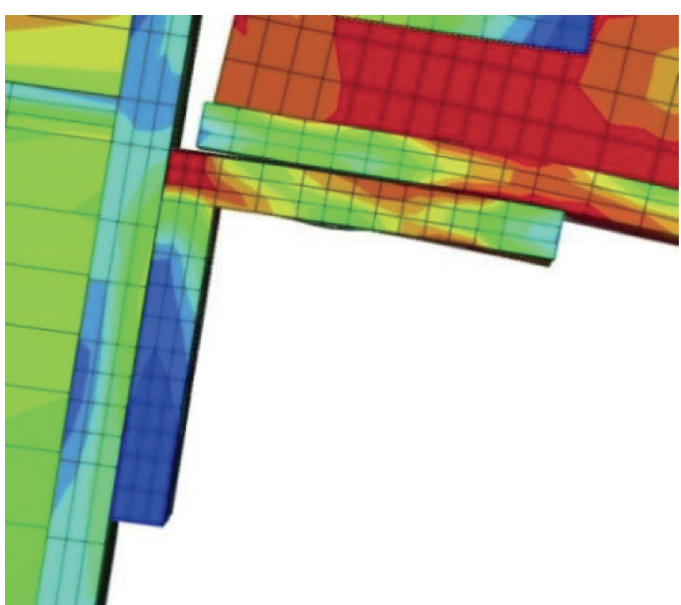

(f)

Figure 12: Comparison of ultimate failure states of SJA-3. (a) Overall test deformation. (b) Gusset angle steel test deformation. (c) Seat angle steel test deformation. (d) Finite element deformation. (e) Gusset angle steel finite element deformation. (f) Seat angle steel finite element deformation.

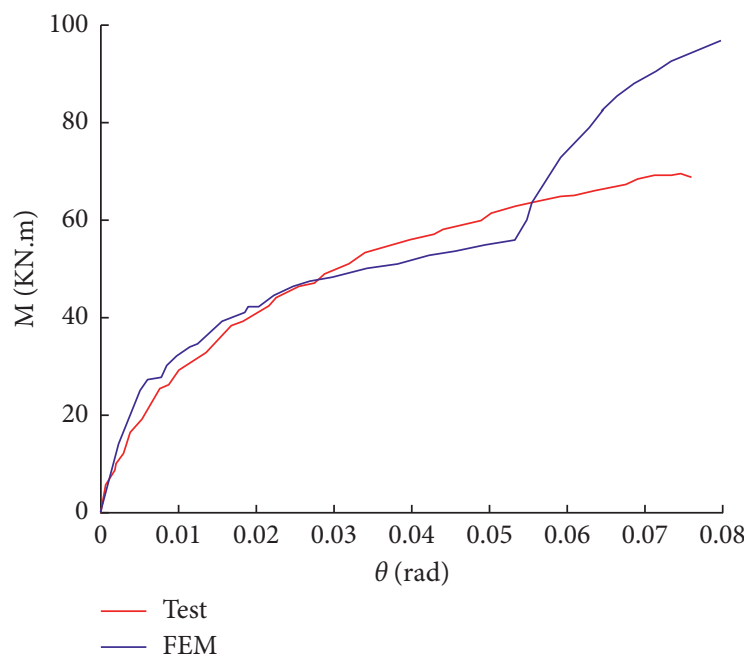

(a)

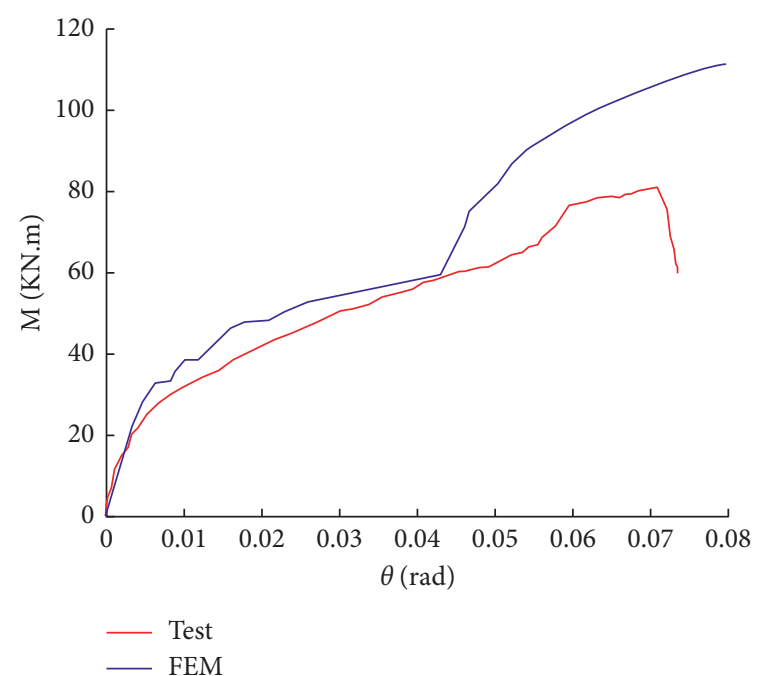

(b)

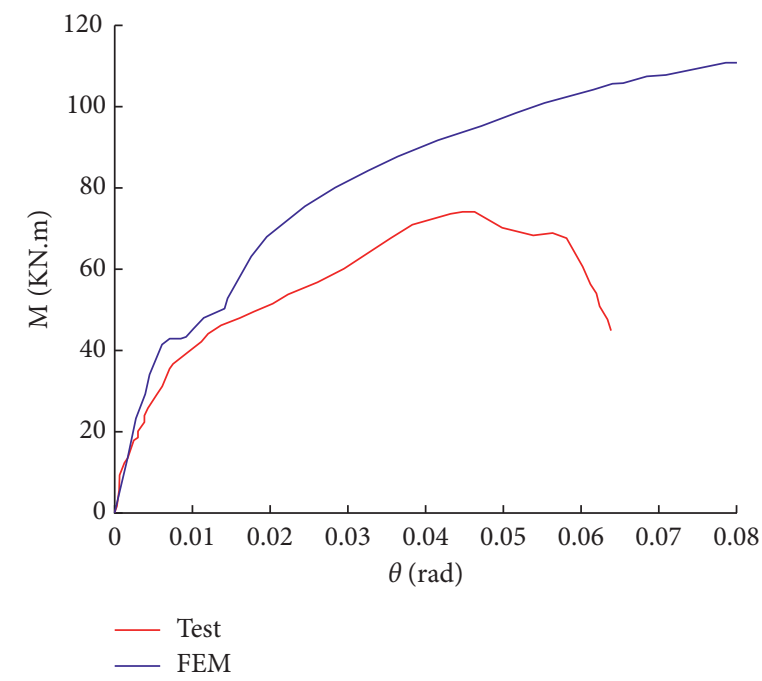

(c)

Figure 13: Comparisons of static loading tests and finite element simulations. (a) SJA-1. (b) SJA-2. (c) SJA-3. 


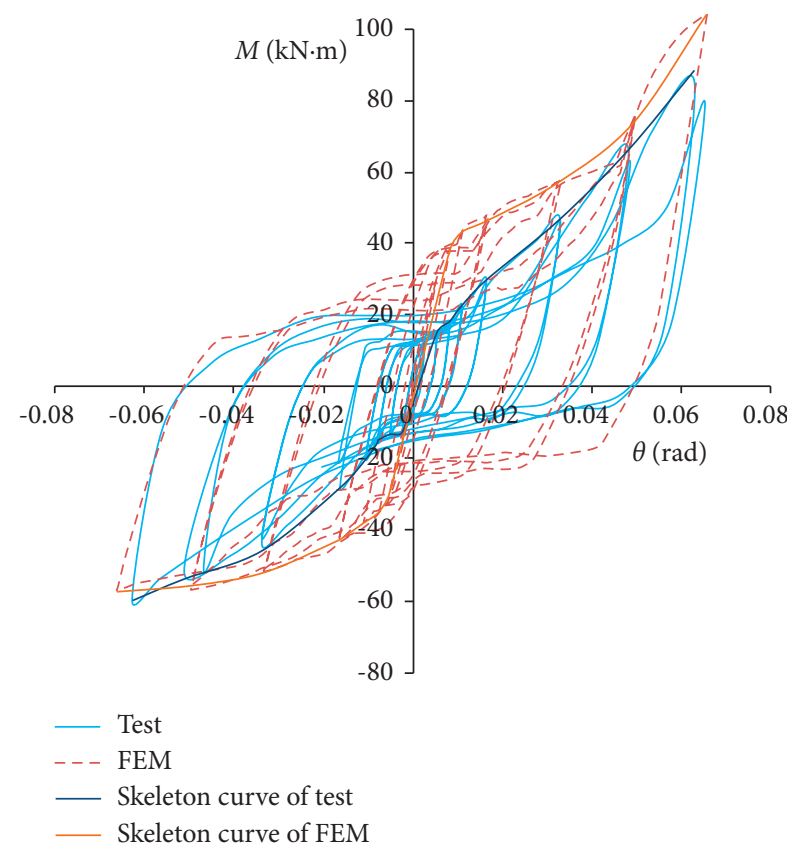

(a)

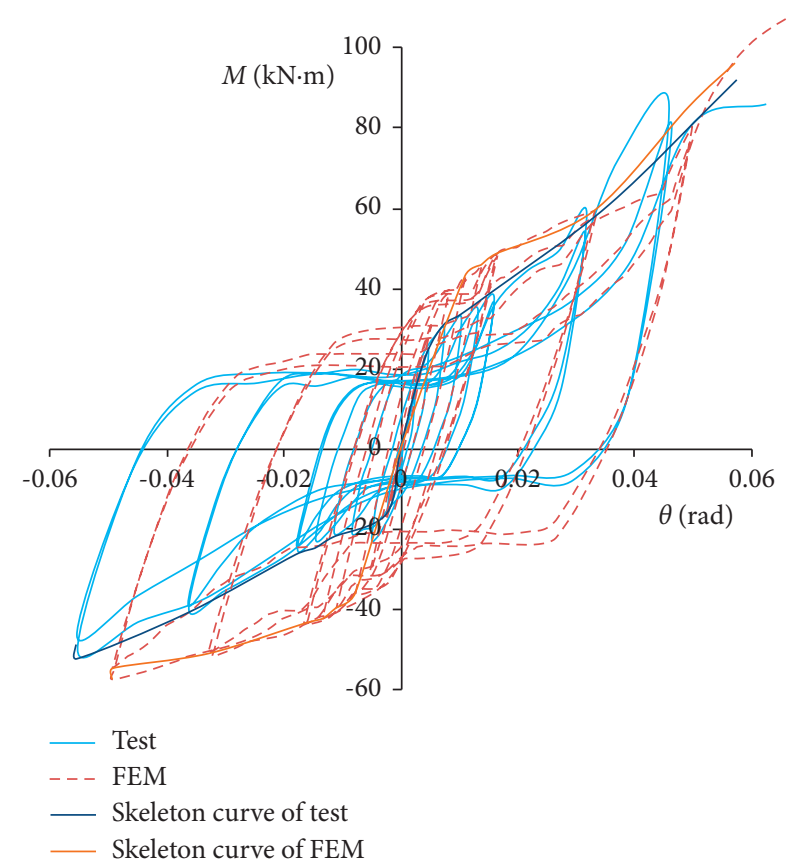

(b)

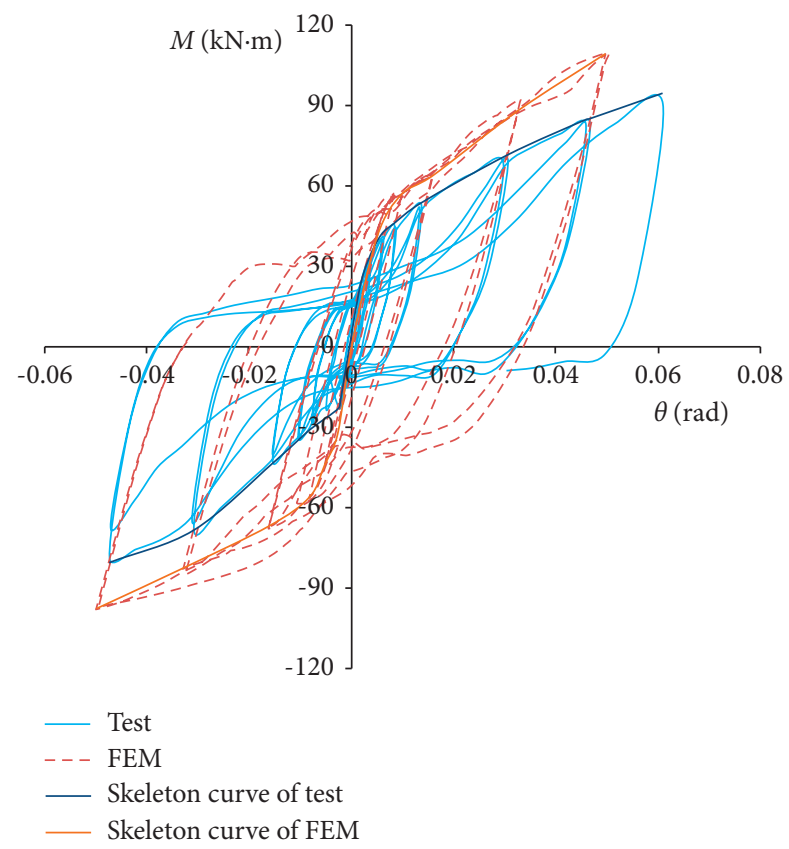

(c)

FIGURE 14: Comparison of moment-angle hysteresis loops. (a) SJB-1. (b) SJB-2. (c) SJB-3.

TABLE 4: Comparison between the SJA experimental and finite element analysis results.

\begin{tabular}{lcccccccc}
\hline & \multicolumn{3}{c}{$\begin{array}{c}\text { Moment bearing capacity } \\
(0.004 \mathrm{rad})(\mathrm{kN} \cdot \mathrm{m})\end{array}$} & \multicolumn{2}{c}{$\begin{array}{c}\text { Moment bearing capacity } \\
(0.03 \mathrm{rad})(\mathrm{kN} \cdot \mathrm{m})\end{array}$} & \multicolumn{3}{c}{$\begin{array}{c}\text { Moment bearing capacity } \\
(0.05 \mathrm{rad})(\mathrm{kN} \cdot \mathrm{m})\end{array}$} \\
& FEM & Test & Ratio & FEM & Test & Ratio & FEM & Test \\
\hline SJA-1 & 20 & 16 & 1.25 & 48 & 49 & 0.98 & 55 & 62 \\
SJA-2 & 25 & 26 & 0.96 & 54 & 50 & 1.08 & 81 & 62 \\
SJA-3 & 27 & 27 & 1 & 82 & 62 & 1.32 & 97 & 71 \\
\hline
\end{tabular}


TABle 5: Comparison between the SJB experimental and finite element analysis results.

\begin{tabular}{|c|c|c|c|c|c|c|c|c|c|}
\hline & \multicolumn{3}{|c|}{$\begin{array}{l}\text { Moment bearing capacity } \\
(0.004 \mathrm{rad})(\mathrm{kN} \cdot \mathrm{m})\end{array}$} & \multicolumn{3}{|c|}{$\begin{array}{l}\text { Moment bearing capacity }(0.03 \mathrm{rad}) \\
(\mathrm{kN} \cdot \mathrm{m})\end{array}$} & \multicolumn{3}{|c|}{$\begin{array}{l}\text { Moment bearing capacity }(0.05 \mathrm{rad}) \\
(\mathrm{kN} \cdot \mathrm{m})\end{array}$} \\
\hline & FEM & Test & Ratio & FEM & Test & Ratio & FEM & Test & Ratio \\
\hline SJB-1 & $24 /-22$ & $15 /-14$ & $1.6 / 1.6$ & $55 /-51$ & $46 /-44$ & $1.2 / 1.16$ & $75 /-57$ & $71 /-54$ & $1.06 / 1.06$ \\
\hline SJB-2 & $26 /-22$ & $25 /-22$ & $1.04 / 1$ & $55 /-51$ & $58 /-36$ & $0.95 / 1.4$ & $81 /-58$ & $80 /-50$ & $1.01 / 1.16$ \\
\hline SJB-3 & $38 /-32$ & $34 /-24$ & $1.12 / 1.3$ & $88 /-80$ & $69 /-68$ & $1.28 / 1.18$ & $110 /-96$ & $84 /-79$ & $1.3 / 1.2$ \\
\hline
\end{tabular}

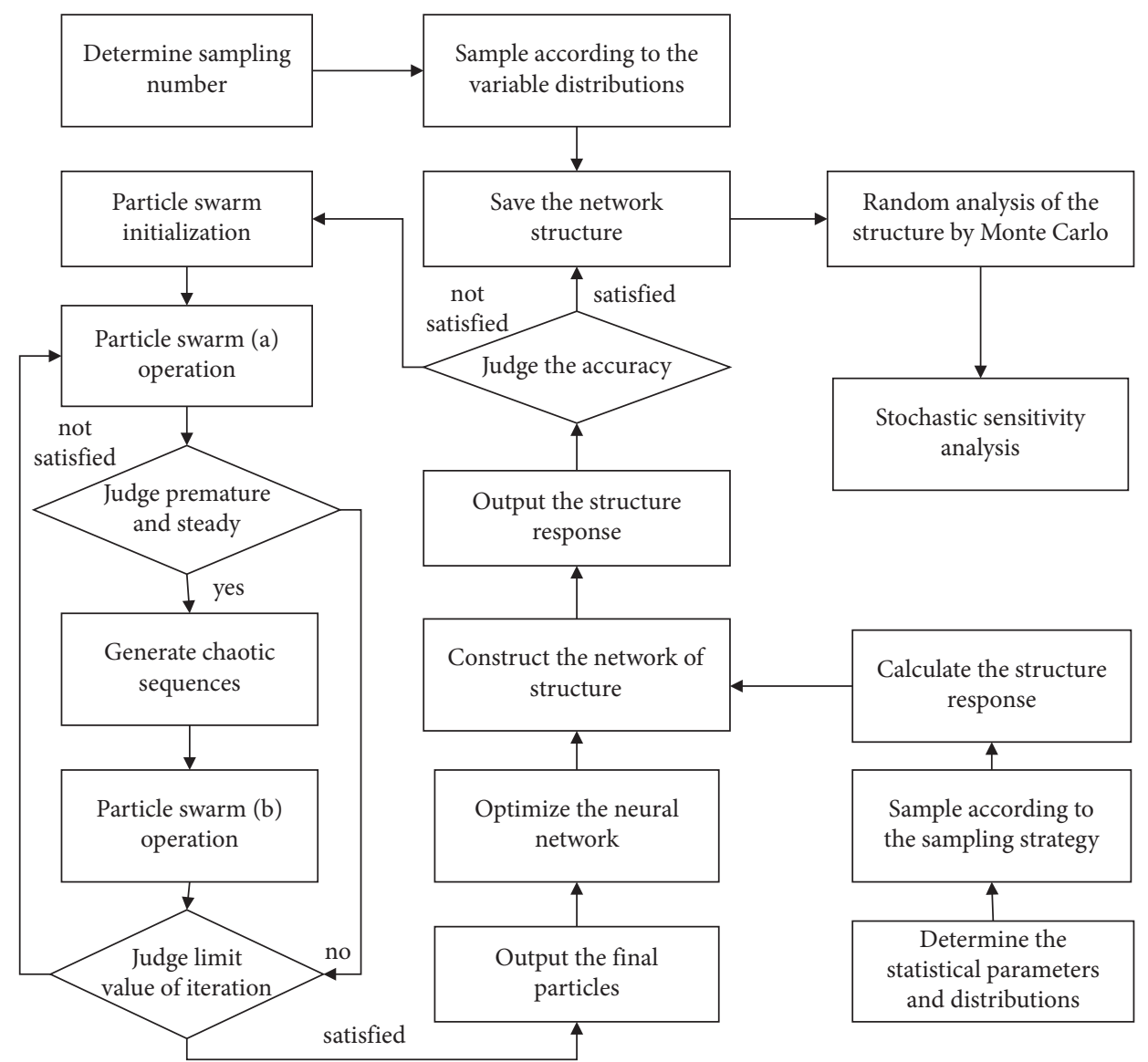

FiguRE 15: Stochastic sensitivity analysis flowchart.

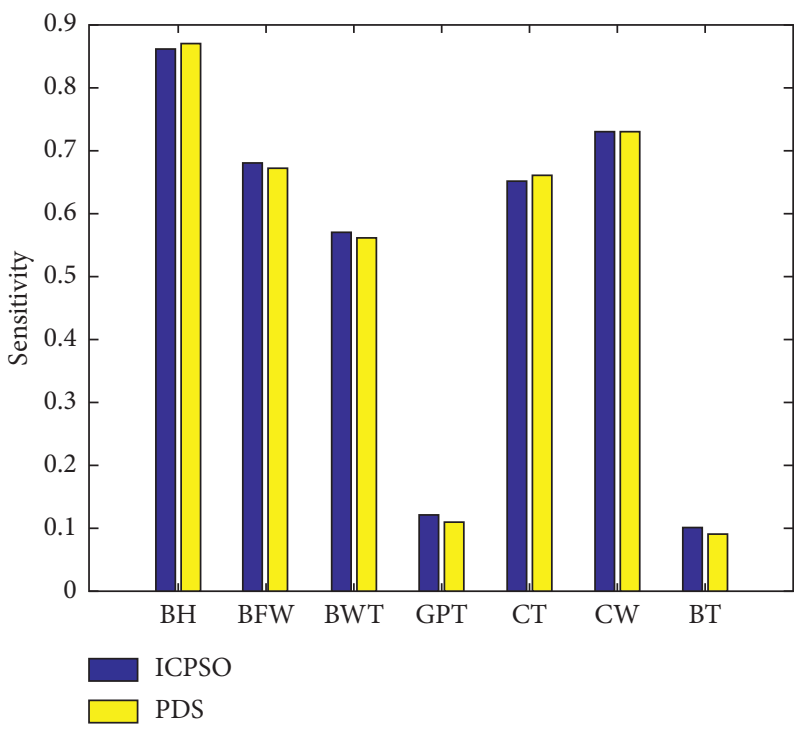

FIGURE 16: Sensitivity coefficient for 5\% variation range. 


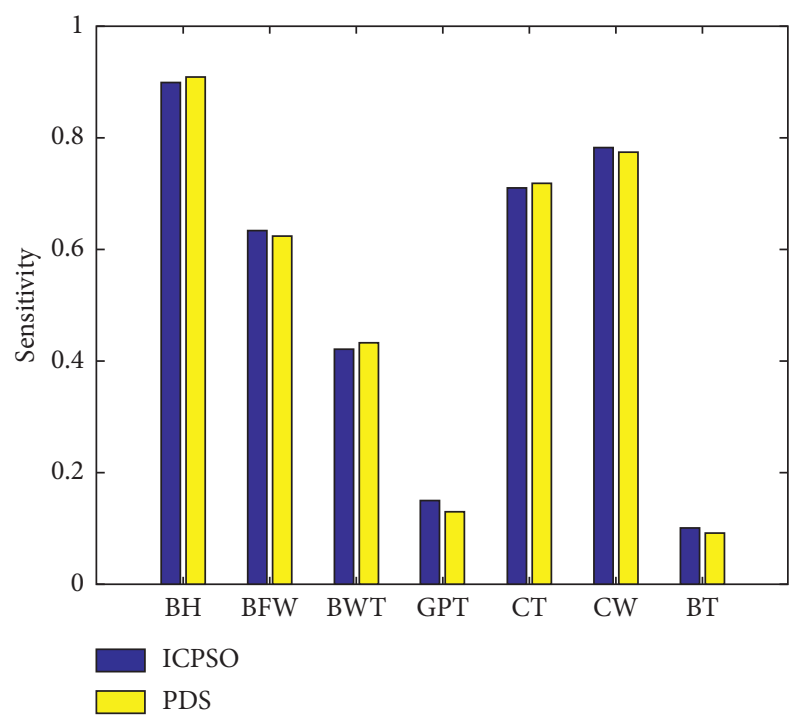

Figure 17: Sensitivity coefficient for $9 \%$ variation range.

$$
\begin{aligned}
& R_{r}=\frac{\sum_{i=1}^{n}\left(x_{i}-\bar{x}\right)\left(y_{i}-\bar{y}\right)}{\sqrt{\sum_{i=1}^{n}\left(x_{i}-\bar{x}\right)^{2}\left(y_{i}-\bar{y}\right)^{2}}}, \\
& S_{r}=\frac{R_{r} / \gamma_{r}}{\sqrt{\sum_{r=1}^{\xi}\left(R r / \gamma_{r}\right)^{2}}}, \\
& \gamma_{r}=\frac{D_{r}}{m_{r}}
\end{aligned}
$$

where $R_{r}$ is the Pearson correlation coefficient of the structure to the $r$-th variable, $S_{r}$ is the sensitivity value of the structure to the $r$-th variable, $\xi$ is the total dimension of the random variable, $n$ is the number of Monte Carlo samples, $x_{i}$ is the random variable, $y_{i}$ is the network output value corresponding to the input random variable $x_{i}, \gamma_{r}$ is the coefficient of variation corresponding to the sample points of the random variable selected by the Monte Carlo simulation, $D_{r}$ is the standard deviation of the $r$-th variable, $m_{r}$ is the mean value of the $r$-th variable, and $S_{r}$ is the sensitivity coefficient of the random variable. The larger the absolute value of the sensitivity coefficient is, the greater influence of the parameter on the static performance of the joint is. The positive and negative values of the sensitivity value represent the positive or negative correlation of the influence of the parameter on the static performance of the joint.

With SJA-3 as a reference model, it was assumed that the column is a rigid body, and the beam height, beam flange width, beam web thickness, gusset plate thickness, connection angle steel thickness, connection angle steel width, and seat angle steel thickness were selected as input parameters. The values were varied within $5 \%$ and $9 \%$ of the original values, and the sensitivities of the variables to the rotation of the joint were analyzed. Latin hypercube sampling was used, and the number of joint models was set to 1000. The flowchart of the structural stochastic sensitivity analysis is shown in Figure 15. These values were compared with the analysis results of the finite element software ANSYS PDS, and the results of the sensitivity values are shown in Figures 16 and 17. BH denotes the beam height, BFW denotes the beam flange width, BWT denotes the beam web thickness, GPT denotes the gusset plate thickness, CT denotes the connection angle steel thickness, CW denotes the connection angle steel width, and BT denotes the seat angle steel thickness. ICPSO denotes the improved chaotic particle swarm optimization network method.

A comparison shows that the errors between the sensitivity values calculated by the ICPSO method and the finite element software were less than $5 \%$. The ICPSO method can more accurately analyze the stochastic sensitivity value of each parameter. Because the variation ranges of the parameters in ANSYS PDS were small, they could not be used for the sensitivity analysis of the same type of joint structure. Thus, the ICPSO method was used to analyze the parameters of the joint with the gusset plate angle connection again, and the variation range of the parameters in this analysis would be increased to $20 \%$. The sensitivity calculation results are shown in Figure 18. When the parameter range increased, the effects of the beam flange width and web thickness on the static performance sensitivity coefficients of the two sets of joints decreased. The sensitivity coefficients for the connection angle steel thickness and width parameters increased, which indicated that the influence of the beam flange width and web thickness on the static performance of the joint decreased, and, thus, these two parameters were not further considered in the subsequent parameter analysis.

\section{Joint Parameter Analysis}

Based on the analysis in Section 4, the influences of the beam height and the width and thickness of the connection angles on the mechanical properties of the joints are examined in this section. The parameter sensitivity coefficient of the seat angle steel was small (because the analysis structure assumed that the seat angle steel was set in Section 4). However, the 


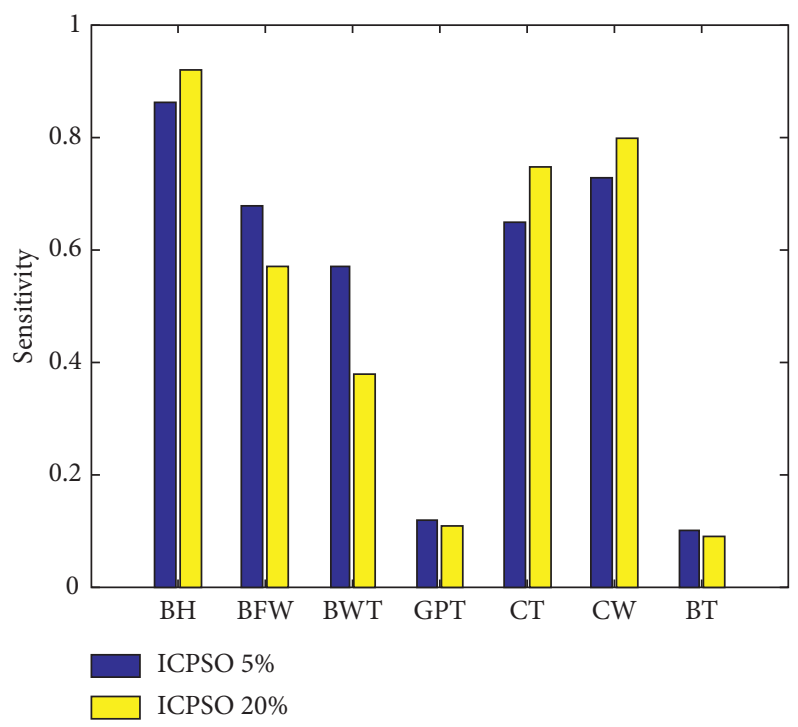

FIGURE 18: Sensitivity coefficients for $5 \%$ and $20 \%$ variation ranges.

influence of adding the seat angle steel on the overall performance of the joint was further studied and is presented in this section.

5.1. Effect of Beam Height. The influence of the change of the beam height on the joint performance was very large. For the joint configuration studied in this paper, under the action of a positive load, the tension area was in the beam, and the influence of the change of the beam height on the joint performance was explored. Model SH-1 was the same as test model SJA-2, and the other models had different beam cross sections and angle parameters. The models of the beam height series are shown in Table 6. The moment-rotation curves and joint performances for different beam heights are shown in Figure 19 and Table 7, respectively. As a result of loading to a certain displacement, the end cross section of the beam was tightened on the bottom flange of the column, resulting in a sudden increase in the bearing capacity. The bearing capacity increased in the later stage in the momentrotation curves of the models.

The increase in the beam height increased the force arm between the tension area and compression area of the entire connection. With the change of the beam height, the initial rotational stiffnesses of the joints were increased by $40 \%$ (SH4), $45 \%$ ( $\mathrm{SH}-3)$, and $26 \%(\mathrm{SH}-2)$ and the ultimate flexural capacities were increased by $29 \%(\mathrm{SH}-4), 30 \%$ (SH-3), and $21 \%$ (SH-2) compared with those of the small first-order beam. The comparison of specimens $\mathrm{SH}-3$ with $\mathrm{SH}-2$ showed that the initial stiffness and strength of the joint increased most significantly. The ratio of the ultimate flexural capacity of the $\mathrm{SH}-2$ joint to the full-section plastic bending moment of the corresponding beam was the largest. As the beam height continued to increase, the ratio decreased.

5.2. Effect of Connection Angle. The thickness and width of the connection angle influenced the initial rotational stiffness and strength of the joint. In this analysis, the thickness
TABLe 6: Size and information of the beam height series model $(\mathrm{mm})$.

\begin{tabular}{lcccc}
\hline Number & Beam cross section & $n$ & Web angle steel & $d$ \\
\hline SH-1/SJA-2 & $194 \times 150 \times 6 \times 9$ & 2 & L75 $\times 10 \times 130$ & 23 \\
SH-2 & $250 \times 125 \times 6 \times 9$ & 3 & L75 $\times 10 \times 190$ & 21 \\
SH-3 & $300 \times 150 \times 6.5 \times 9$ & 4 & L75 $\times 10 \times 250$ & 16 \\
SH-4 & $346 \times 174 \times 6 \times 9$ & 5 & L75 $\times 10 \times 310$ & 9 \\
\hline
\end{tabular}

Note. $n$ is the number of rows of bolts; $d$ is the spacing between the beam flange and web angle.

and width of the connection angle were varied within the normal size range, and the other parameters were fixed. Information related to the angular series model is shown in Table 8. Figure 20 shows the moment-rotation curves of the joints with different thicknesses or widths of the connection angle. Changing the thickness or width of the connection angle had significant effects on the initial rotational stiffness and moment bearing capacity of the joint. Table 9 shows the effects on the joint performance caused by changing the size of the connection angle when the beam height was 194 and $250 \mathrm{~mm}$.

5.2.1. Influence of Connection Angle Steel Thickness. The change of the joint performance from SH1C-1 to SH1C-2 and from SH1C-3 to SH1C-5 (or from SH2C-1 to SH2C-2 and from $\mathrm{SH} 2 \mathrm{C}-3$ to $\mathrm{SH} 2 \mathrm{C}-5$ ) showed that, with the increase in the angle thickness, the yield moments, initial rotational stiffnesses, and ultimate flexural bearing capacities of the joints were improved to some extent. For specimens SH1C-3 to SH1C-5, the thickness of the angle steel was increased in $2 \mathrm{~mm}$ increments, and the initial rotational stiffnesses increased by $8.7 \%$ (SH1C-4) and $4.4 \%$ (SH1C-5). The increase in the joint performance from SH1C-3 to SH1C-4 was about two times higher than that from SH1C-4 to SH1C-5. The ultimate bending bearing capacity showed similar variations. When the thickness of the angle increased to a certain value, 


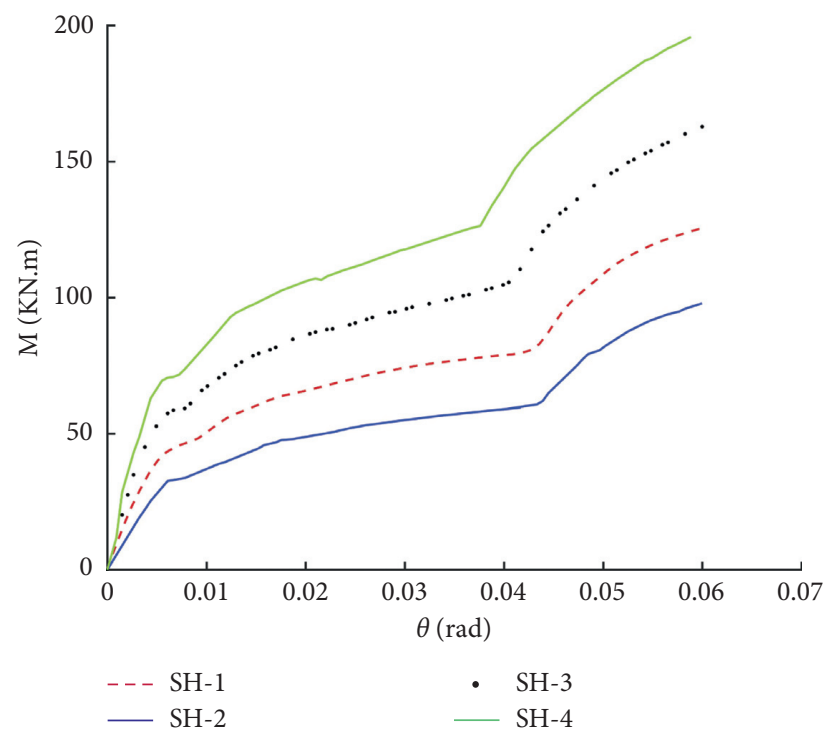

FIgURE 19: Moment-rotation curves of joints with different beam heights.

Table 7: Performance with different beam heights (mm).

\begin{tabular}{lcccc}
\hline & SH-1 & SH-2 & SH-3 & SH-4 \\
\hline$K$ & 6796 & 9502 & 13780 & 17383 \\
$M_{u}$ & 97 & 125 & 162 & 196 \\
$K_{i} / K_{1}$ & 1 & 1.40 & 2.03 & 2.56 \\
$M_{u i} / M_{1}$ & 1 & 1.28 & 1.65 & 2.00 \\
$M_{u} / M_{p l}$ & 1.52 & 1.65 & 1.44 & 1.32 \\
$K_{i} / K_{l}$ & 3.5 & 4.3 & 4.1 & 3.9 \\
\hline
\end{tabular}

Note. $M_{u}$ is the ultimate plastic moment $(\mathrm{kN} \cdot \mathrm{m}) ; M_{p l}$ is the plastic moment of the beam's total cross section $(\mathrm{kN} \cdot \mathrm{m}) ; K$ is the initial rotational stiffness of the joint $\left(\mathrm{kN} \cdot \mathrm{m} \cdot \mathrm{rad}^{-1}\right) ; K_{l}$ is the coefficient of linear stiffness.

the joint performance tended to be stable, and then the effect of increasing the thickness of the angle on the performance of the joint was gradually reduced. The increase in the length of the angle limbs weakened the thickness effect on the joint performance. The weakening effect was negative, which was not conducive to improving the joint performance.

5.2.2. Influence of Connection Angle Steel Width. As the length of the angle increased, the line spacing of the corresponding bolts increased (the Code for Design of Steel Structure provided the arrangement of the equilateral angles with the single-row bolts; when the side length was $75 \mathrm{~mm}$, the corresponding line spacing was $40 \mathrm{~mm}$, and when the side length was $80 \mathrm{~mm}$, the corresponding line spacing was $45 \mathrm{~mm}$ ), which caused the stiffnesses and bearing capacities of the joints to decrease. Thus, when comparing SH1C-2 with SH1C-3 (or SH2C-2 with SH2C-3), the angle thickness was constant, the side length of the equilateral angle limbs changed from 75 to $80 \mathrm{~mm}$, and the initial rotational stiffness and moment bearing capacity of the joint decreased by $-6 \%$ and $-9 \%$, respectively ( $-5 \%$ and $-8 \%$ in series $\mathrm{H} 2$, respectively).

The comparison of SH1C-2 with SH1C-4 (or SH2C-2 with $\mathrm{SH} 2 \mathrm{C}-4$ ) shows that the latter angle thickness was $2 \mathrm{~mm}$
TABLE 8: Dimensions and information of the angular thickness series model $(\mathrm{mm})$.

\begin{tabular}{lcc}
\hline Number & Beam cross section & Connection angle steel \\
\hline SH1C-1 & $194 \times 150 \times 6 \times 9$ & L $75 \times 8 \times 130$ \\
SH1C-2/SJA-2 & $194 \times 150 \times 6 \times 9$ & L75 $\times 10 \times 130$ \\
SH1C-3 & $194 \times 150 \times 6 \times 9$ & L $80 \times 10 \times 130$ \\
SH1C-4 & $194 \times 150 \times 6 \times 9$ & L $80 \times 12 \times 130$ \\
SH1C-5 & $194 \times 150 \times 6 \times 9$ & L $80 \times 14 \times 130$ \\
SH2C-1 & $250 \times 125 \times 6 \times 9$ & L $75 \times 8 \times 190$ \\
SH2C-2 & $250 \times 125 \times 6 \times 9$ & L75 $\times 10 \times 190$ \\
SH2C-3 & $250 \times 125 \times 6 \times 9$ & L $80 \times 10 \times 190$ \\
SH2C-4 & $250 \times 125 \times 6 \times 9$ & L $80 \times 12 \times 190$ \\
SH2C-5 & $250 \times 125 \times 6 \times 9$ & L $80 \times 14 \times 190$ \\
\hline
\end{tabular}

larger than the former, while the side length of the latter angle $(80 \mathrm{~mm})$ was $5 \mathrm{~mm}$ longer than the former angle $(75 \mathrm{~mm})$. The results showed that although the $80 \mathrm{~mm}$ side length thickness increased by $2 \mathrm{~mm}$, the initial rotational stiffness and moment bearing capacity were not significantly increased; they increased by $2 \%$ and $6 \%$, respectively. The initial rotational stiffness and moment bearing capacity increased by $1.5 \%$ and $4 \%$ in series $\mathrm{H} 2$, respectively. The joint parameters interacted with each other. The increase in the beam height weakened the influence of the angle changes on the joint performance. The initial rotational stiffness and strength of the joints increased with the increase in the angle thickness. When the angle thickness increased to a certain value, the effect gradually decreased. As the side length of the angle increased, the corresponding line spacing of the bolts increased, which would lead to a decrease in the joint stiffness and bearing capacity.

5.3. Effect of Seat Angle. The seat angle was included, and the influence of the thickness change of the seat angle on the mechanical properties of the joints was analyzed. Five thicknesses, $6,8,10,12$, and $14 \mathrm{~mm}$, were selected, and they 


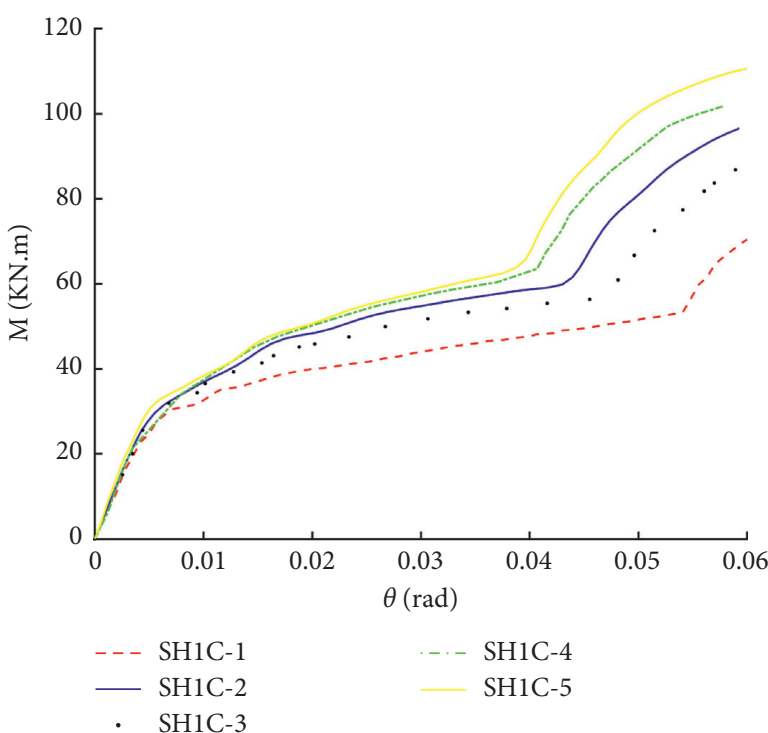

(a)

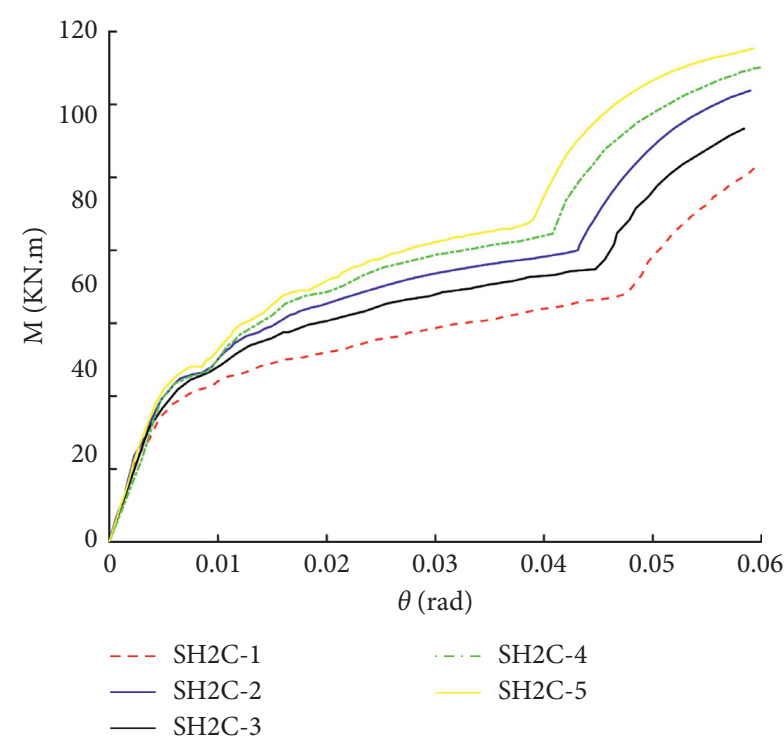

(b)

FiguRE 20: Bending moment-rotation curves of different thicknesses and widths of the connection angle. (a) Series of beam H1. (b) Series of beam $\mathrm{H} 2$.

TABLE 9: Joint properties of angle steel with different thicknesses and widths of the connection angle.

\begin{tabular}{lccccc}
\hline Number & $M_{e}$ & $K$ & $M_{u}$ & $K_{i} / K_{2}$ & 0.90 \\
SH1C-1 & 20 & 6101 & 70 & 1 & $M_{u i} / M_{u 2}$ \\
SH1C-2 & 26 & 6796 & 97 & 0.94 \\
SH1C-3 & 23 & 6379 & 88 & 1.02 & 1 \\
SH1C-4 & 26.5 & 6936 & 103 & 1.07 & 0.91 \\
SH1C-5 & 28 & 8240 & 110 & 0.90 & 1.06 \\
SH2C-1 & 26 & 9575 & 103 & 0.95 & 0.82 \\
SH2C-2 & 29 & 8985 & 125 & 1.02 & 0.92 \\
SH2C-3 & 28 & 9648 & 115 & 1.06 \\
SH2C-4 & 30 & 10032 & 130 & 1.06 \\
SH2C-5 & 34 & 136 & 1.09 \\
\hline
\end{tabular}

Note. $M_{u}$ is the ultimate plastic moment $(\mathrm{kN} \cdot \mathrm{m}) ; M_{e}$ is the joint's yielding moment $(\mathrm{kN} \cdot \mathrm{m}) ; K$ is the initial rotational stiffness of the joint $\left(\mathrm{kN} \cdot \mathrm{m} \cdot \mathrm{rad}{ }^{-1}\right) ; K_{l}$ is the coefficient of linear stiffness.

were compared with specimen S-1 without a seat angle. The size information of the seat angle model is shown in Table 10. The moment-rotation curves of the joints with the seat angle are shown in Figure 21, and the corresponding joint performances are shown in Table 11.

Compared with S-1, the initial rotational stiffness of SD1 increased by $35 \%$, and the moment bearing capacity when the rotational angle was 0.03 rad increased by $51 \%$, which indicated that setting the seat angle could improve the stiffness and strength of the joint significantly.

Based on the analysis above, the beam height of the joint and the thickness and width of the connection angle all influenced the performance of the joint. Within the approximate ranges of parameters for the joint, the greater the beam height was, the larger the angle thickness was; the smaller the angle width was, the better the joint performance was. When these parameters were increased to certain values simultaneously, the effect was gradually reduced. Thus, the individual component parameters cannot simply be increased to obtain the ideal connection joint. The joint parameters would influence each other; for example, the increase in the side length of the connection angle would weaken the influence of the thickness on the performance of the joint. When satisfying the other engineering constraints, decreasing the side length of the connection angle and increasing the thickness of the angle would be more efficient for improving the joint performance. Likewise, increasing the beam height would weaken the effect of changing the angle on the performance of the joint.

Considering the cost and structural space, based on the design notion of "strong joint-weak connected member," it is suggested to select the SH-2 beam-column joint. When the seat angle was set for the beam-column joint with a gusset plate angle connection, the thickness of the seat angle was set to meet the structural requirements of the connection and for construction convenience, which is the best strategy. Choosing the appropriate angle thickness and side length has vital significance for the 
TABle 10: Sizes and information of the seat angle model (mm).

\begin{tabular}{lccc}
\hline Number & Beam section & Web angle steel & $t$ \\
\hline S-1 & $194 \times 150 \times 6 \times 9$ & L75 $\times 10 \times 130$ & - \\
SD-1 & $194 \times 150 \times 6 \times 9$ & L75 $\times 10 \times 130$ & \\
SD-2 & $194 \times 150 \times 6 \times 9$ & L $75 \times 10 \times 130$ & \\
SD-3/SJA-3 & $194 \times 150 \times 6 \times 9$ & L75 $\times 10 \times 130$ & \\
SD-4 & $194 \times 150 \times 6 \times 9$ & L75 $\times 10 \times 130$ & \\
SD-5 & $194 \times 150 \times 6 \times 9$ & L75 $\times 10 \times 130$ & 10 \\
\hline
\end{tabular}

Note. $t$ is the thickness of the seat angle.

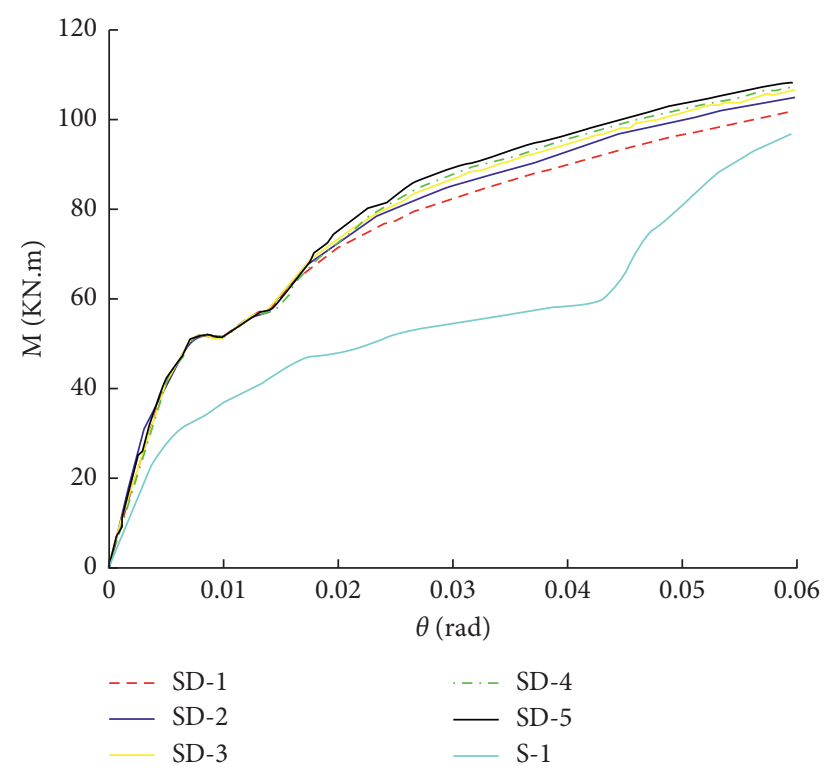

FIGURE 21: Moment-rotation curves of seat angle steel joint.

TABLE 11: Effect of seat angle steel on joint.

\begin{tabular}{|c|c|c|c|c|c|c|}
\hline Number & S-1 & SD-1 & SD-2 & SD-3 & SD-4 & SD-5 \\
\hline$M_{e}$ & 26 & 35 & 35 & 35 & 35 & 35 \\
\hline$K$ & 6796 & 9147 & 9218 & 9260 & 9341 & 9371 \\
\hline$M_{P}$ & 55 & 83 & 85 & 88 & 88.6 & 89 \\
\hline$M_{u}$ & 97 & 102 & 105 & 106 & 107 & 108 \\
\hline$K_{i} / K_{1}$ & 1.00 & 1.35 & 1.36 & 1.36 & 1.37 & 1.38 \\
\hline$M_{p i} / M_{p 1}$ & 1.00 & 1.51 & 1.55 & 1.60 & 1.61 & 1.62 \\
\hline$M_{u \mathrm{i}} / M_{u 1}$ & 1.00 & 1.05 & 1.08 & 1.09 & 1.10 & 1.10 \\
\hline
\end{tabular}

Note. $M_{P}$ is the plastic moment when the rotation angle was $0.03 \mathrm{rad}(\mathrm{kN} \cdot \mathrm{m}) ; M_{p l}$ is the plastic moment of the beam's total cross section $(\mathrm{kN} \cdot \mathrm{m})$.

practical structural performance of the joint. After a negative load was applied to a certain rotational angle and the seat angle fractured, the top angle fractured when a positive load was applied. This failure mode could make full use of the energy dissipation capacity of the joint components. The optimal choice for the connection angle was a $10 \mathrm{~mm}$ thickness and a $75 \mathrm{~mm}$ length.

\section{Conclusions}

The JGA has high initial rotational stiffness, strength, and ductility, which are favorable for seismic design. The mechanical properties are quite different from the stiffened angle connection joints. It is not suitable to simplify the joint as an articulate joint or the gusset plate as stiffener for the design. 
In this study, a reasonable design of the connection angle and beam height of the JGA is proposed, which provides a reference for the structural design and optimization. Experiments showed that the deformation of the column flange was restricted after adding the stiffener, which could prevent the premature yield of the column flange, thus improving the stiffness and strength of the JGA. After the beam-column joint with a gusset plate angle connection yielded, the degradation of the negative initial rotational stiffness and strength of the joint was more severe than that for the positive values. Adding a seat angle could significantly improve the positive and negative initial rotational stiffnesses and strengths of the joint, which provided the joint with a good energy dissipation capacity.

The ICPSO network could accurately evaluate the influence of each of the joint components on the overall performance of the structure. This approach can be extended for the same type of joint, and, thus, the analysis is no longer limited by the numerical range of ANSYS PDS. With the stochastic sensitivity analysis of the joint structure, the component parameters that have a significant influence on the structure can be analyzed, avoiding blind finite element simulations. The indices that influence the mechanical properties of the joints are the core area of the gusset plate, the beam height, and the addition of the seat angle. Increasing the height of the beam or the height of the gusset plate (gusset angle steel) increases the force arm between the tension and compression zones, and it significantly improves the mechanical properties, such as the initial rotational stiffness and strength of the joint. Adding seat angle steel can significantly improve the initial rotational stiffness and strength of the joint (compared with the same form of the joint without a seat angle), while increasing the thickness of the seat angle has little effect on the mechanical properties of the joint. It is recommended to choose beam section $\mathrm{SH} 2$ and a connection angle with a $10 \mathrm{~mm}$ thickness and a $75 \mathrm{~mm}$ length for the joint design.

\section{Data Availability}

The data that support the findings of this study are available from the corresponding author upon reasonable request.

\section{Conflicts of Interest}

The authors declare that there are no conflicts of interest regarding the publication of this article.

\section{Acknowledgments}

This study was supported by the National Natural Science Foundation of China (Grant nos. 51808357 and 51638009). The authors thank LetPub (https://www.letpub.com/) for its linguistic assistance during the preparation of this manuscript.

\section{References}

[1] W. A. Thornton, "Bracing connections for heavy construction," Engineering Journal AISC, vol. 21, no. 3, pp. 139-148, 1984.
[2] C. M. Hewitt and W. A. Thornton, "Rationale behind and proper application of the ductility factor for bracing connections subjected to shear and transverse loading," Engineering Journal, vol. 41, no. 1, pp. 3-6, 2004.

[3] R. C. Ward, "Improved seismic performance of gusset plate connections," Journal of Structural Engineering, vol. 134, no. 6, pp. 890-901, 2008.

[4] W. B. Kim and H. H. Park, "Study on the ultimate strength of gusset plate-circular hollow section (CHS) joint stiffened with rib-plate by end restraint," Journal of Korean Society of Steel Construction, vol. 24, no. 4, pp. 523-533, 2012.

[5] M. R. H. Far, M. Z. Jumaat, and R. T. S. Vahid, "Nonlinear analysis of load-deflection testing of reinforced one-way slab strengthened by carbon fiber reinforced polymer (CFRP) and using artificial neural network (ANN) for prediction," International Journal of the Physical Sciences, vol. 6, no. 13, pp. 3054-3061, 2011.

[6] C. V. Dung, H. Sekiya, S. Hirano, T. Okatani, and C. Miki, “A vision-based method for crack detection in gusset plate welded joints of steel bridges using deep convolutional neural networks," Automation in Construction, vol. 102, pp. 217-229, 2019.

[7] S. Ebrahimi, S. R. Mirghaderi, and S. M. Zahrai, "Proposed design procedure for gusset plate dimensions and force distribution at its interfaces to beam and column," Engineering Structures, vol. 178, pp. 554-572, 2019.

[8] S. Kishiki, S. Yamada, and A. Wade, "Experimental evaluation of structural behavior of gusset plate connections in BRB frame bsystem," in Proceedings of the 14th World Conference on Earthquake Engineering, pp. 12-17, Beijing, China, October 2008.

[9] J. Liu and A. Astaneh-Asl, "Cyclic testing of simple connections including effects of slab," Journal of Structural Engineering, vol. 126, no. 1, pp. 32-39, 2000.

[10] M. Ryota, T. Katsuto, S. Ben, T. Toru, M. Saki, and H. Yuma, "Global stability of chevron buckling restrained braced frames with various gusset plates and secondary beams," Journal of Structural and Construction Engineering (Transactions of AIJ), vol. 84, no. 758, pp. 563-573, 2019.

[11] W. Zhang, Y. Zhou, and Y. Zhang, "Influence of gusset plate connections on the secondary moments in beams and columns of braced frames," Journal of Harbin Institute of Technology, vol. 45, no. 006, pp. 1-7, 2013.

[12] L. A. Fahnestock, E. M. Hines, R. Tremblay et al., "Reserve capacity and implications for seismic collapse prevention for low-ductility braced frames in moderate seismic regions," Tenth National Conference on Earthquake Engineering, pp. 21-25, Anchorage, AK, USA, 2014.

[13] C. Fang, M. C. H. Yam, J. J. R. Cheng, and Y. Zhang, "Compressive strength and behaviour of gusset plate connections with single-sided splice members," Journal of Constructional Steel Research, vol. 106, pp. 166-183, 2015.

[14] C. Fang, M. C. H. Yam, X. Zhou, and Y. Zhang, "Postbuckling resistance of gusset plate connections: behaviour, strength, and design considerations," Engineering Structures, vol. 99, pp. 9-27, 2015.

[15] W. Zhang, L. Zeng, P. Gardoni, and X. Qi, "Experimental investigation and low-cycle fatigue behavior of I-shaped steel bracing members with gusset plate connections," Thin-Walled Structures, vol. 162, no. 2, Article ID 107593, 2021.

[16] R. Khademi-Zahedi and P. Alimouri, "Finite element model updating of a large structure using multi-setup stochastic subspace identification method and bees optimization 
algorithm," Frontiers of Structural and Civil Engineering, vol. 13, no. 4, pp. 965-980, 2019.

[17] J. Chun, J. Song, and G. H. Paulino, "System-reliability-based design and topology optimization of structures under constraints on first-passage probability," Structural Safety, vol. 76, pp. 81-94, 2019.

[18] T.-H. Nguyen and D.-D. Nguyen, "Reliability assessment of steel-concrete composite beams considering metal corrosion effects," Advances in Civil Engineering, vol. 2020, no. 3, 15 pages, Article ID 8817809, 2020.

[19] H. Wang, L. Tang, and G. Y. Li, "Adaptive MLS-HDMR metamodeling techniques for high dimensional problems," Expert Systems with Applications, vol. 38, no. 11, pp. 1411714126, 2011.

[20] X. Dong and Z. Wang, "The method of model approximation for the analysis of semi-rigid connection with parameter correlation," The Open Civil Engineering Journal, vol. 10, no. 1, pp. 738-750, 2016.

[21] X. Dong, Z. Wan, and J. R. Pan, "Stochastic sensitivity analysis for models with parameter correlation and model approximation method," Journal of Information and Computational Science, vol. 12, no. 2, pp. 657-672, 2015.

[22] F. Cadini, S. S. Lombardo, and M. Giglio, "Global reliability sensitivity analysis by Sobol-based dynamic adaptive kriging importance sampling," Structural Safety, vol. 87, no. 6, Article ID 101998, 2020.

[23] X. Dong and Z. Wang, "Stochastic sensitivity analysis method based on correlation parameters and hybrid neural network," Journal of Building Structures, vol. 36, pp. 149-157, 2015.

[24] Y. N. Li, X. Dong, Z. Wang, and K. Qin, "Research on mechanical properties of angle beam - column joint with gusset plate," in Proceedings of the 2020 2nd International Academic Exchange Conference on Science and Technology innovation, vol. 233, GuangZhou China, July 2021.

[25] S. Wilkinson, G. Hurdman, and A. Crowther, "A moment resisting connection for earthquake resistant structures," Journal of Constructional Steel Research, vol. 62, no. 3, pp. 295-302, 2006. 